\title{
NeuroRegulation
}

\section{Functional Neural Network Connectivity in Myalgic Encephalomyelitis}

\author{
Marcie L. Zinn ${ }^{*}$, Mark A. Zinn, and Leonard A. Jason \\ Center for Community Research, DePaul University, Illinois, USA
}

\begin{abstract}
Myalgic Encephalomyelitis (ME) is a chronic illness with debilitating neurocognitive impairment that remains poorly understood. Previous studies have characterized cognitive deficits as a process by which brain abnormalities are inferred from pre-established testing paradigms using neuroimaging with low temporal resolution. Unfortunately, this approach has been shown to provide limited predictive power, rendering it inadequate for the study of neuronal communication between synchronized regions. More recent developments have highlighted the importance of modeling spatiotemporal dynamic interactions within and between large-scale and small-scale neural networks on a millisecond time scale. Here, we focus on recent emergent principles of complex cortical systems, suggesting how subtle disruptions of network properties could be related to significant disruptions in cognition and behavior found in ME. This review, therefore, discusses how electrical neuroimaging methods with time-dependent metrics (e.g., coherence, phase, cross-frequency coupling) can be a useful approach for the understanding of the cognitive symptoms in ME. By providing a platform for utilizing real-time alterations of the perpetual signals as an outcome, the disruptions to higher-level cognition typically seen in ME can be readily identified, creating new opportunities for better diagnosis and targeted treatments.
\end{abstract}

Keywords: myalgic encephalomyelitis; chronic fatigue syndrome; functional connectivity; resting-state networks; quantitative EEG (qEEG); electrical neuroimaging

Citation: Zinn, M. L., Zinn, M. A., \& Jason, L. A. (2016). Functional Neural Network Connectivity in Myalgic Encephalomyelitis. NeuroRegulation, 3(1), 28-50. http://dx.doi.org/10.15540/nr.3.1.28

*Address correspondence to: Marcie L. Zinn, PhD, Center for Community Research, DePaul University, 990 W. Fullerton Avenue, Chicago, IL 60614-3504, USA. Email: mzinn1@depaul.edu

Copyright: () 2016. Zinn et al. This is an Open Access article distributed under the terms of the Creative Commons Attribution License (CC-BY).

Edited by:

Rex Cannon, PhD, Neural Potential, Boynton Beach, Florida, USA

Reviewed by:

Rex Cannon, PhD, Neural Potential, Boynton Beach, Florida, USA Randall Lyle, PhD, Mount Mercy University, Cedar Rapids, Iowa, USA

\section{Introduction}

The 19th-century neurologist John Hughlings Jackson (1835-1911) once said that a major impediment in understanding a neurological disease is a lack of a method for doing so (York \& Steinberg, 2011). This problem has challenged the investigation of neurological disease for over a century and, more recently, has posed a significant challenge for the study of Myalgic Encephalomyelitis $(\mathrm{ME}) .{ }^{1}$ ME is a complex, multi-system disease that has remained poorly understood despite decades of empirical research (Afari \& Buchwald, 2003; Cockshell \& Mathias, 2014; Jason, Zinn, \& Zinn, 2015). The most debilitating symptoms pertain to

\footnotetext{
${ }^{1}$ For the sake of clarity, throughout this article we will use ME even though a number of studies use Chronic Fatigue Syndrome (CFS) to describe their patient samples.
}

neurocognitive dysfunction; that is, symptoms such as memory impairment, poor concentration and attention, and slow information processing speed are reported by nearly all (at least $90 \%$ of) patients as having a severe impact on their everyday living (Capuron et al., 2006; Cho, Skowera, Cleare, \& Wessely, 2006; Cook, O'Connor, Lange, \& Steffener, 2007; Lange et al., 2005; Marshall, Forstot, Callies, Peterson, \& Schenck, 1997; Michiels \& Cluydts, 2001; Ropper \& Samuels, 2009; Sandman, Barron, Nackoul, Goldstein, \& Fidler, 1993; Yancey \& Thomas, 2012). This contrasts with a neuropsychological research base documenting only modest levels of cognitive impairment (Attree, Arroll, Dancey, Griffith, \& Bansal, 2014; Cockshell \& Mathias, 2014; DeLuca, Genova, Capili, \& Wylie, 2009) and a paucity of studies investigating the relationship with fatigue severity, sleep quality, and quality of life (Christodoulou et al., 1998; Metzger \& 
Denney, 2002; Tiersky et al., 2001; Tiersky, Johnson, Lange, Natelson, \& DeLuca, 1997). These paradoxical results might be explainable, however, if one considers the historical context whereby neuropsychological and neuroimaging findings typically do not align well with patient self-reports for patients with brain diseases (DeLuca, 2005; Hillary \& DeLuca, 2007; Luria, 1980).

A number of studies using neuropsychological test batteries have provided some support for neurocognitive deficits in ME (Cairns \& Hotopf, 2005; Chen, Feng, Zhao, Yin, \& Wang, 2008; Deluca et al., 2004; Majer et al., 2008; Michiels \& Cluydts, 2001; Thomas \& Smith, 2009), while others did not (Cope, Pernet, Kendall, \& David, 1995; Krupp, Sliwinski, Masur, Friedberg, \& Coyle, 1994; Short, McCabe, \& Tooley, 2002). Neurocognitive deficits reported by patients include a lack of mental clarity/mental confusion, sustained attention deficits, verbal working memory deficits, longer reaction times, trouble with multitasking or learning, and problems with response inhibition (Christley, Duffy, Everall, \& Martin, 2013; Cockshell \& Mathias, 2010; Dobbs, Dobbs, \& Kiss, 2001; Hou et al., 2013; Wearden \& Appleby, 1997). Notably, these findings have been shown by several authors to be unrelated to psychiatric issues, such as depression, anxiety, etc. (Cockshell \& Mathias, 2010, 2012, 2014; Dickson, Toft, \& O'Carroll, 2009; Smith, Behan, Bell, Millar, \& Bakheit, 1993) as well as pain and medication effects (Attree et al., 2014; Christodoulou et al., 1998; Cockshell \& Mathias, 2014; Dickson et al., 2009; Santamarina-Perez et al., 2011).

The assessment of psychiatric influences on neurological symptoms has been studied for a long period of time (Strauss, Sherman, \& Spreen, 2006) and remnants of this debate coupled with the continued absence of an established biomarker appear to be, in part, what is contributing to controversy over whether ME is a manifestation of psychopathology (Cope \& David, 1996) or an independent neurological disorder (DeLuca et al., 2009). Some investigators have suggested that patients with ME may be exaggerating cognitive symptoms (Ocon, 2013), setting unrealistic expectations (Metzger \& Denney, 2002) or underperforming due to lack of effort (Goedendorp, Bleijenberg, \& Knoop, 2014). Others posit that emotional or psychological factors are likely responsible for ME symptomology (Cope et al., 1995; Fry \& Martin, 1996; Mariman et al., 2013; Warren, Langenberg, \& Clauw, 2013; White, 2010), suggesting environmental effects (Wearden \& Appleby, 1997) or cultural effects, both resulting in sickness behavior (Abbey \& Garfinkel, 1991). More broadly, among neurological disorders overall, it is known that the prevalence of depressive symptoms in people with neurological disorders is higher than that of non-depressed people by nearly 40 percent (Fleminger, Oliver, Williams, \& Evans, 2003; Stanton \& Carson, 2015).

ME is often misdiagnosed as depression (Griffith \& Zarrouf, 2008), and co-morbid depression in patient samples has generated debate over whether it is primary or secondary to ME neurocognitive impairment (Twisk, 2014). For those patients with both conditions, it has been shown that ME and depression are separate disorders sharing some common features (Hawk, Jason, \& Torres-Harding, 2006; Maes, 2011; Pazderka-Robinson, Morrison, \& Flor-Henry, 2004). Depression in ME does not exhibit symptoms of Beck's cognitive triad (pessimism about the self, world, and future), a core feature of major depressive disorder (Hawk, Jason, \& Torres-Harding, 2006). Fatigue, another controversial symptom of ME, is a core feature of major depressive disorder and other forms of depression, and may share a common neuroimaging feature with $\mathrm{ME}$, that is, activity in the anterior cingulate along with its connections (Angelakis \& Lubar, 2002; Olvet et al., 2015; Zhang et al., 2015). The primary difference, however, between ME fatigue and fatigue in major depression has been demonstrated empirically to be a reaction to physical activity; people with ME feel considerably worse after physical activity (called post-exertional malaise, PEM), while people with major depression feel better (Griffith \& Zarrouf, 2008). This is an important distinction, since PEM is a central feature of ME (LaManca et al., 1998; Nijs et al., 2010), and inducing patients with depression to maintain some physical activity is a core strategy for improvement (Vancampfort, Stubbs, Venigalla, \& Probst, 2015). The presence of depression (or other Axis 1 disorders) in ME could be the phenotype of a dysregulated central nervous system with the somatic symptoms as a consequence of the disease process. $^{2}$ Regardless of disease etiology, it is well known that neurocognitive impairment found in ME exerts deleterious consequences upon the quality of life for many individuals, and psychiatric factors do not fully account for their level of functional disability (Christodoulou et al., 1998). The problem of finding out what drives this form of neurocognitive

\footnotetext{
${ }^{2}$ According to DSM-IV-TR, patients with psychiatric comorbidity would be classified under Axis III with the psychiatric problem being secondary general medical condition, unless it can be shown that the primary psychiatric condition existed before the onset of ME.
} 
dysfunction with linkage of brain function to patient symptoms therefore warrants further attention.

\section{Neuroimaging Studies in ME}

One crucial issue for $\mathrm{ME}$ is a better understanding of the neurocognitive events that underlie behavior and cognition following illness onset. The past several decades have been a time of considerable fluctuation in views of neurocognitive dysfunction for ME seen in the contradictory findings since the early 1990s, while neuroimaging investigations have been unable to establish a clear biological biomarker or signature specific to ME. In a recent literature review, Fischer and colleagues (Fischer et al., 2014) found neuroanatomical differences (using magnetic resonance imaging; MRI) between some patients with ME and healthy controls, but there is still no unifying explanation for the diversity of, or at times absence of, structural findings. Results in some studies have suggested involvement of white matter (Lange et al., 1999; Natelson, Cohen, Brassloff, \& Lee, 1993), but other studies found only grey matter abnormalities (de Lange et al., 2005; de Lange et al., 2004; de Lange et al., 2008; Okada, Tanaka, Kuratsune, Watanabe, \& Sadato, 2004; Puri et al., 2012) and two studies reported no significant abnormalities in ME (Cope \& David, 1996; Perrin, Embleton, Pentreath, \& Jackson, 2010). Regarding functional characteristics in ME, cerebral hypoperfusion was found using single-photon emission computed tomography (SPECT) in some (Biswal, Kunwar, \& Natelson, 2011; Costa, Tannock, \& Brostoff, 1995; Ichise et al., 1992; Schwartz, Komaroff, et al., 1994) but not all studies (Lewis et al., 2001; MacHale et al., 2000; Schmaling, Lewis, Fiedelak, Mahurin, \& Buchwald, 2003). Results of metabolic activity from two positron emission tomography (PET) studies were inconclusive (Siessmeier et al., 2003; Tirelli et al., 1998), but abnormalities involving neurotransmitter biosynthesis was suggested in a line of more recent studies (Cleare, Messa, Rabiner, \& Grasby, 2005; Nakatomi et al., 2014; Yamamoto et al., 2012). Task-evoked studies using blood-oxygen-leveldependent functional MRI (BOLD fMRI) detected various functional differences in neural activity in $\mathrm{ME}$ related to motor imagery (de Lange et al., 2004) and verbal working memory tasks (Lange et al., 2005) depending upon increasing task load (Caseras et al., 2006) and fatigue-inducing tasks (Caseras et al., 2008; Cook et al., 2007; Tanaka et al., 2006). These studies, however, need replication with larger sized sample groups. Taken together, the foregoing results of ME neuroimaging findings are inconclusive and remain unclear. Despite discovering newer ways to assess the symptoms commonly reported in
ME neurocognitive impairment, current findings do not fully account for patient symptoms.

\section{Functional Specialization (Segregation)}

The primary reason for the disparity between some findings may be due to an over-reliance on classical functional specialization (localizationism models) to examine ME neurocognitive dysfunction. The functional specialization model rests on the premise that individual brain regions are specific and segregated (Deco, Jirsa, \& Friston, 2012; Menon, 2012; Rabinovich, Friston, \& Varona, 2012). Gay and colleagues (Gay et al., 2015) were first to document regional activation profiles in ME using a functional connectivity approach, suggesting this paradigm may hold promise for identifying the properties of neurocognitive impairment in ME. Due to the knowledge derived from the NIH Human Brain Project in the 1990s, the field of cognitive neuroscience has now established a framework for which complex brain systems can be studied and quantified to support new understandings of cognition and behavior (Thatcher, 2011). Functional brain connectivity is currently the new paradigm focusing on distributed neuronal units or the synchronization of activation of brain regions at rest or when performing a particular cognitive task (Bazhenov \& Makeig, 2012; Catani, 2011; Catani, Bodi, \& Dell'Acqua, 2012; Rabinovich, Friston, et al., 2012; Thatcher, 2012). Distributed organization within large scale dynamic systems involving multiple brain regions which are spatially distant but functionally linked act together to form a given network (Catani, Dell'Acqua, et al., 2012; Friston, 2010; Rabinovich, Friston, et al., 2012; Thatcher, 2011). Within this system, modular organization, common in complex systems to maximize efficiency, is achieved through use of a relatively small set of modules and hubs, whereby local groupings (clusters) of neurons rely on a small number of long distance connections in order to maximize the metabolic expense of wiring (Havlicek et al., 2015; Menon, 2012; van Straaten \& Stam, 2013). In this manner, dysregulation found within and among nodes and hubs of functionally specialized networks may form the primary basis for arriving at a clinical interpretation of symptoms (Thatcher, 2011, 2012, 2015; Thatcher, North, \& Biver, 2005; Thatcher et al., 2001).

\section{Models of ME Pathogenesis}

Despite decades of research, the definitive causes of ME remain unknown. A common quote in medicine, "the absence of evidence is not evidence for absence," could apply to ME with some similarity, for example, to Lyme disease where the pathogen 
was serendipitously identified after 72 years (Pachner, 2012). There are nonetheless some promising models, which appear to explain patient symptoms. An infectious pathogen in the etiology of ME has been proposed but has not yet been confirmed. Schwartz, Komaroff, et al. (1994) hypothesized ME may be caused by a viral infection of neurons, glia, or vasculature. Support for the deficient metabolism in ME was offered in some PET and SPECT imaging studies (Costa et al., 1995; Schwartz, Garada, et al., 1994; Tirelli et al., 1998). Morris and Maes (2012) proposed an immune-inflammatory model for ME, which accounts for fatigue, post-exertional malaise, and neurocognitive symptoms. Their model suggested the term "post activity relapse" be used for delayed abnormal responses to negligible increases in physical or mental activity that resemble acute phases of influenza (fatigue, malaise, hyperalgesia, brain fog). The authors further suggested that fatigue in ME was suppressing brain function and modulating the autonomic system. In a combined voxel-based analysis of four MRI imaging types (T1 and T2 weighted, grey matter and white matter volume) performed by Barnden et al. (2011), brainstem abnormalities in ME were found to be associated with increasing fatigue duration and hemodynamic scores; white matter atrophy and neuroinflammation in the midbrain was accompanied by impaired cerebrovascular autoregulation.

In a comprehensive review, Dickinson (1997) argued that a viral infection could cause multiple small lesions in the ascending arousal system (AAS). Due to its densely compact size, even microscopic damage to the brainstem could lead to severe disruptions to sleep state transitions, contributing to fluctuations in cognitive symptomology (Saper, Fuller, Pedersen, Lu, \& Scammell, 2010; Wright, Lowry, \& LeBourgeois, 2012; Wulff, Gatti, Wettstein, \& Foster, 2010). In a follow-up study by Barnden, Crouch, Kwiatek, Burnet, and Del Fante (2015) which controlled for depression and anxiety, the brainstem was implicated again and compromised nerve conduction in the midbrain was associated with upregulation of myelination in the prefrontal cortex (PFC; dysregulated signal conduction velocity). The upregulation of myelin (relative to the diameter of axons) may relate to the energy consumption of the fibers mediating the PFC to increase signal conduction velocity and firing capacity (de Hoz \& Simons, 2015) at the expense of brain efficiency (more energy consuming ionic channel, axonal transport processes; increased thickness consuming more energy and taking up more space).

\section{Brain Efficiency Hypothesis and ME}

The brain's energy expenditure is critically important given that it weighs approximately 3 pounds, yet it consumes about $20-40 \%$ blood oxygen consumption, a disproportionate rate of consumption (Raichle, 2010; Shulman, Rothman, Behar, \& Hyder, 2004). A significant amount of this baseline energy is budgeted for neuronal signaling processes and glutamate neurotransmission by excitatory glutamatergic neurons (Shulman et al., 2004). Bullmore and Sporns (2012) explain the state of affairs in terms of parsimony; there is a continual drive to minimize the metabolic costs while supporting or creating adaptively valuable functional connectivity. Within this system, the brain is seen as a continual process of negotiating these trade-offs. Glutamate, the chief excitatory neurotransmitter in the brain, is a primary factor, particularly due to its crucial involvement in coupling neuronal activity with glucose utilization and lactate production through reuptake by astrocytes (Pellerin \& Magistretti, 1994). Glutamate also plays a key role in regulating $\alpha-$ Amino-3-hydroxy-5-methyl-4-isoxazolepropionic acid (AMPA) receptors for making adjustments to synaptic strength (Bredt \& Nicoll, 2003). Nucleotide and protein synthesis secondarily contribute to energy demand, expanding size of synapses, creation of new synapses during wakefulness, regulating excitatory loops, and long-term potentiation (Kennedy, Beale, Carlisle, \& Washburn, 2005). Electrical demands of neurons are more costly than blood oxygen and glucose, and cortical excitability is modulated by fluctuations in the delivery of glucose and adenosine triphosphate energy to neurons (Raichle, 2010).

However, it remains unclear as to how metabolic failures within various brain regions affect neurocognitive function in ME. Recent evidence regarding many neurological disorders suggests that metabolic dysfunction can lead to neuronal hyperexcitability and aberrant neuronal network activities, causing neural dysregulation and producing cognitive deficits through chronic activation of the stress response (McEwen et al., 2015). This can be seen in several diseases whereby metabolic changes are known to cause neural dysfunction (Stranahan \& Mattson, 2008), often with the cognitive effects beginning well before the physiological ones are evident (Halassa \& Haydon, 2010). Energy deficits can induce unfavorable changes in resting membrane potentials and gamma-aminobutyric acid (GABA-induced) anionic currents, leading to neuronal hyperactivity that may initiate a cascade of pathological events 
(Holmgren \& Scheffer, 2010). Another possible model posits that neurocognitive dysfunction in ME may emanate from disruption of top-down control within the prefrontal cortex with its normal ability to exert influence over the hypothalamus in modulating sleep/wake parameters (Barnden et al., 2015; Wright et al., 2012). Regardless of the underlying etiology, the "brain fog" (Ocon, 2013) in ME might be described as a generalized failure in the brain's ability to allocate resources in a flexible manner, resulting in widespread inefficiency and producing a state that poses a threat to the adaptive mediation of homeostatic processes. These nonlinear processes may be interactions between the metabolic system, stress system, and inflammatory responses in the immune system (McEwen, 2006). The metabolic changes can, therefore, be taken as signs of allostatic load (effects of chronic stress) and though many of the changes are only partly understood, we are beginning to understand the chronic disruption in these systems and how it affects cognition in chronic disease, especially in ME.

A recurrent theme throughout the ME literature, neuroimaging in particular, is that patients are underperforming, compensating, and otherwise utilizing neural resources more inefficiently than healthy controls (Caseras et al., 2006; Cook et al., 2007; de Lange et al., 2004; Lange et al., 2005; Tiersky et al., 1997). Behaviorally, patients are typically found to be less responsive, less vigilant, and slower to react or initiate movements (Tanaka et al., 2006; Thomas \& Smith, 2009; Van Den Eede et al., 2011). Gay et al. (2016) found evidence of reduced functional connectivity in patients with ME. Hypo-connectedness suggests there are fewer links to distant neurons, possibly driven by a homeostatic need to reduce energy costs. All nodes within brain networks can exhibit the same functional properties but with varying degrees of efficiency and the resulting propensity for reorganization. Compensatory activity in the brain appears to be a mechanism of complex self-organizing systems via homeostatic processes (Hellyer, Jachs, Clopath, \& Leech, 2015). Nodes are small interacting units in the topology of a network while hubs are units that occupy a highly central position in the network. Due to costly metabolic demands, hubs are more vulnerable to pathology (Crossley et al., 2014), and their failure tends to cause greater disruption within a given network hierarchy (Stam, 2014). Hubs are also crucial for information integration coming in from other widely distributed brain regions (van den Heuvel \& Sporns, 2013). The controllability of finite timings within densely connected areas facilitating brain states depend on the underlying integrity of structural connections (Gu et al., 2015; Hagmann et al., 2008). Local "small world" networks operate with local groupings (clusters) of neurons relying on a small number of short-distance connections (thereby maximizing the energy "expense" of wiring) while long distance connections between nodes and modules are inherently less stable (van Straaten \& Stam, 2013). Therefore, dysregulation found within and among specialized functional networks may form the primary basis for arriving at a clinical interpretation of neurocognitive symptoms (Menon, 2011; Stam, 2014).

\section{Examining Spatiotemporal Dynamics in ME}

Another important facet of ME cognitive dysfunction may be the degree to which measurable spatiotemporal changes in normal dynamic brain function is occurring, thereby contributing to the diminishment of cognitive processes involved in attention, memory, and information transfer rates. Understanding neurocognitive impairment at the spatiotemporal level may sufficiently describe what may be happening to patients because these global state interactions may underpin disturbances to homeostatic systems and represent a failure to adapt in ME, thereby producing measurable deficits in cognition (Rabinovich, Afraimovich, Bick, \& Varona, 2012; Rabinovich, Friston, et al., 2012). Highly time-dependent circuits of information flow involve the coordination of time-series segments of large neural populations distributed widely within the brain (Buzsáki, 2006), and the assessment of these subtleties requires analysis of network interactions with high spatiotemporal precision, across extended time periods (Tristan, Rulkov, Huerta, \& Rabinovich, 2014). Maintained by an excitatory re-entrant process that alter their dynamics in the face of differing task demands, cognition and action depend upon time-based stability within large-scale brain circuits (Elson, Huerta, Abarbanel, Rabinovich, \& Selverston, 1999; Hellyer et al., 2015), whether it is engagement with the environment through sensory systems or by disengagement from the environment, using learned experiences (Sporns, 2013). Neurons are continuously in motion, but it is their synchronization or lack of synchronization that might be most important when studying cognitive control processes (Klimesch, Freunberger, Sauseng, \& Gruber, 2008). Accordingly, spatiotemporal dynamics are thought to emerge from homeostatic "tuning" of various factors such as 1) structural network topology, 2) neural noise, 3) time delays, 4) connectivity strength, 5) dynamic balance of excitation/inhibition, and 6) interactions with glial cells (e.g., changes in myelin microarchitecture; de 
Hoz \& Simons, 2015). All of these factors operate within a narrow window of parameters, outside of which they operate within a pathological state (Buzsáki \& Watson, 2012; Hellyer et al., 2015). Each factor co-varies with arousal levels and cognitive state, factors which are vital to performance levels of memory, perceptual, and problem-solving tasks (Tang, Rothbart, \& Posner, 2012).

Diverse brain activity visible in the electroencephalogram (EEG) demonstrates how brain function is continually dynamic and in constant flux (Raichle, 2011), and it reflects the spatially diffuse synchronization of large masses of neuronal assemblies which give rise to cognition and behavior (Thatcher, 2015). Quantitative EEG (qEEG) methods are well suited for the task of capturing temporal dynamics at the millisecond time-scale synchronization of brain processes which are largely invisible to other imaging modalities such as fMRI, SPECT, and PET (Thatcher, 2015). Diffusion tensor imaging (DTI) provides an excellent static depiction of white matter and non-dynamic structural mapping of the cortex. fMRI offers excellent spatial resolution but the examination of high temporal fluctuations in connectivity models is limited to constraints of the hemodynamic signal: indirect measurement of neuronal activity with low temporal resolution (on the order of seconds; Poldrack, Mumford, \& Nichols, 2011). The spatial resolution of EEG has been adequately addressed through advancements in electrical neuroimaging, a promising approach for noninvasive examination of spatiotemporal interactions in the millisecond domain for mapping of intracortical sources in four dimensions (space and time frequency) through using a variety of distributed inverse methods (Grech et al., 2008).

Electrical neuroimaging involves source analysis procedures to examine the cortex of all frequency bands (delta, theta, alpha, beta, and gamma) through spectrally transformed recordings from the scalp surface using 19-channel EEG (M.A. Zinn et al., 2014). Accurate estimations of the intracranial activity can be achieved with application of inverse methods such as low-resolution electromagnetic tomography (LORETA) and more recent iterations: standardized LORETA (sLORETA) and exact LORETA (eLORETA; Pascual-Marqui, Esslen, Kochi, \& Lehmann, 2002; Pascual-Marqui, Lehmann, et al., 2011; Pascual-Marqui, Michel, \& Lehmann, 1994). These methods, which allow cross-validation through voxel by voxel coregistration to PET, SPECT, FMRI for matching data to standard coordinate systems, have been used to characterize spatiotemporal dynamics in patients with a wide variety of clinical conditions such as Alzheimer's disease (Babiloni, Binetti, et al., 2004; Babiloni, Cassetta, et al., 2006; Canuet et al., 2012; Gianotti, Künig, Faber, et al., 2008; Gianotti, Künig, Lehmann, et al., 2007), mild cognitive impairment (Babiloni, Carducci, et al., 2013; Babiloni, Del Percio, et al., 2014; Babiloni, Frisoni, et al., 2006), other dementias (Nishida et al., 2011; Styliadis, Kartsidis, Paraskevopoulos, loannides, \& Bamidis, 2015), epilepsy (Besenyei et al., 2012; Canuet et al., 2011; Clemens et al., 2010), Parkinson's disease (Babiloni et al., 2011; Moazami-Goudarzi, Sarnthein, Michels, Moukhtieva, \& Jeanmonod, 2008), multiple sclerosis (Papageorgiou et al., 2007), chronic fatigue syndrome (Sherlin et al., 2007), congestive heart failure (Vecchio et al., 2015), obstructive sleep apnea (Toth, Faludi, Wackermann, Czopf, \& Kondakor, 2009), migraine (Clemens et al., 2008), tinnitus (Vanneste et al., 2010), and Down's syndrome (Velikova et al., 2011). LORETA has also been used to investigate neuropsychiatric conditions including locked-in syndrome (Babiloni et al., 2010), anhedonia (Wacker, Dillon, \& Pizzagalli, 2009), obsessive-compulsive disorder (Jones \& Bhattacharya, 2014; Olbrich et al., 2013; Velikova et al., 2010), posttraumatic stress disorder (Todder et al., 2012), and major depression (Olbrich, Trankner, Chittka, Hegerl, \& Schonknecht, 2014). Crossvalidation has been demonstrated in multimodal studies combining LORETA with blood oxygen dependent fMRI (Mulert et al., 2004; Musso, Brinkmeyer, Mobascher, Warbrick, \& Winterer, 2010; Vitacco, Brandeis, Pascual-Marqui, \& Martin, 2002), and structural MRI (Worrell et al., 2000), PET (Dierks et al., 2000; Pizzagalli et al., 2004). Validation of LORETA is further supported by localization findings from invasive, intracranial recordings in humans, as established in several studies of epilepsy and cognitive event-related potentials (Volpe et al., 2007; Zumsteg, Friedman, Wieser, \& Wennberg, 2006; Zumsteg, Lozano, Wieser, \& Wennberg, 2006). The promising aspect of this method is that it allows researchers to create dynamic causal models of brain networks and mental states, assessing the informational status of the individual nodes, linkages and clustering of connections (Pascual-Marqui et al., 2011). Further advancements have even made it possible to examine cortical dynamics and interrogate causal information flow (Pascual-Marqui et al., 2014).

Results using LORETA have already been reported by Sherlin et al. (2007) by investigating twins with $M E$, finding slowing of electrical activity in deeper brain structures and parts of the limbic system. 
Exploring this further, M. A. Zinn et al. (2014) collected and evaluated pilot data using eLORETA to analyze the current source density in 50 patients with ME compared to 50 healthy controls. This study found that patients had significantly higher current source density within delta $(1-3 \mathrm{~Hz})$ affecting widespread bilateral portions of the frontal lobe and limbic lobe. Beta sources $(19-21 \mathrm{~Hz})$ were also reduced in the medial posterior parietal regions affecting the sensorimotor region and posterior cingulate in patients. Furthermore, increased delta sources were linked to the Multi-dimensional Fatigue Inventory (MFI-20) reduced motivation subscale in many regions of the left frontal lobe, with maxima localized to Broca's area (Smets, Garssen, Bonke, \& De Haes, 1995). The co-occurrence of delta and beta in these brain regions may have provided empirical evidence for a neurobiological basis for patient symptomology including impairment to higher cortical functioning. More importantly, dysregulation in structures such as the parahippocampal gyrus, anterior cingulate, and insula, prefrontal cortex, and orbitofrontal gyrus could explain neurocognitive symptoms in patients (e.g., problems involving attention, memory, multi-tasking, goal-directedness, etc.). Limbic regions, when dysregulated, have generally not been associated with universal domains of attention, working memory and executive function, but instead have been associated with symptoms such as apathy, abulia, reduced motivation, and impaired attention states known as negative (deficit) symptoms (Kuzis, Sabe, Tiberti, Dorrego, \& Starkstein, 1999; McPherson, Fairbanks, Tiken, Cummings, \& Back-Madruga, 2002). Therefore, the importance of negative symptoms in
ME was underscored in this sample. The association of the $\mathrm{MFI}-20$ reduced motivation scale and eLORETA sources further suggested a psychophysiological model may be requisite to understanding this phenomenon.

Use the same dataset, M. L. Zinn et al. (2014) also examined qEEG peak alpha frequency (PAF) computed within the $8-12 \mathrm{~Hz}$ frequency band based on each participant's EEG. Mixed ANOVA results found significantly decreased PAF over $58 \%$ of the entire cortex in patients with ME when compared to controls. There were significant differences in PAF at 11 electrode sites $(p<0.05)$. Two hierarchical multiple regression models found that subjective scores on both the MFI-20 and FSS (Fatigue Severity Scale; Krupp, LaRocca, et al., 1989) as separate dependent variables predicted fatigue. Findings were consistent with previous reports of reduced efficiency of thalamocortical connections in patients with ME suggesting that PAF measurement may have both diagnostic and prognostic value in patients. The widespread nature of the PAF dysregulation strongly suggests subcortical pathology with some authors suggesting this pathology involves the brainstem (Barnden et al., 2011; Dickinson, 1997; Tirelli et al., 1998). These studies have set the stage for the next steps using network analyses and dynamic relationships to understand a number of cognitive domains where ME deficits have been found (see Table 1 which summarizes the qEEG case-control studies on patients with ME during wakefulness). 


\section{Table 1}

Case-control qEEG studies involving ME patients during wakefulness

\begin{tabular}{|c|c|c|c|}
\hline $\begin{array}{l}\text { Author } \\
\text { (Year) }\end{array}$ & $N$ & Investigation & $\begin{array}{l}\text { Behavioral } \\
\text { Measures }\end{array}$ \\
\hline $\begin{array}{l}\text { Prasher, } \\
\text { Smith, and } \\
\text { Findley } \\
(1990)\end{array}$ & $\begin{array}{l}25 \text { patients } \\
\text { divided into } 2 \\
\text { groups with } \\
\text { enteroviral } \\
\text { antigen VP1 } \\
\text { test positive } \\
\& \text { negative } \\
25 \text { healthy } \\
\text { controls }\end{array}$ & $\begin{array}{l}\text { Event-related potentials } \\
\text { recorded from } \mathrm{Fz}, \mathrm{Cz} \text {, } \\
\mathrm{Pz} \\
\text { Visual potentials: } \\
\text { Checkerboard pattern } \\
\text { Somatosensory potentials: } \\
\text { Median nerve } \\
\text { stimulation from cervical } \\
\text { spine } \\
\text { Cognitive potentials: } \\
\text { Reaction time to audio tone } \\
\text { in ms }\end{array}$ & None \\
\hline $\begin{array}{l}\text { Billiot, } \\
\text { Budzynski, } \\
\text { and } \\
\text { Andrasik } \\
\text { (1997) }\end{array}$ & $\begin{array}{l}28 \text { patients } \\
28 \text { healthy } \\
\text { controls } \\
\text { matched for } \\
\text { age and } \\
\text { gender }\end{array}$ & $\begin{array}{l}\text { EEG activity recorded from } \\
\text { Cz to measure peak } \\
\text { frequency and } \\
\text { theta/beta ratio during } \\
\text { eyes closed and serial } \\
7 \text { s conditions }\end{array}$ & $\begin{array}{l}\text { Profile of Fatigue- } \\
\text { Related } \\
\text { Symptoms } \\
\text { (PFRS cognitive } \\
\text { difficulty factors } \\
\text { neg. correlated } \\
\text { with serial } 7 \mathrm{~s} \text { ) }\end{array}$ \\
\hline
\end{tabular}

Siemionow, 8 patients

Fang,

Calabrese, 8 healthy

Sahgal, and controls

Yue (2004) matched by

age

Sherlin et

al. (2007)

17 pairs of monozygotic twins discordant for ME

Flor-Henry, 61 female Lind, and patients

Koles

(2010)
80 female controls

\footnotetext{
EEG source analysis using LORETA 3D imaging method during eyes closed condition and serial 7s.
}

Significant Findings

Greater P3 latency and duration was found in ME sample.

Results permit subgrouping patients by P3 amplitude: those with attention problems and those with slower information processing speed.

Eyes closed:

- $\mathrm{ME}>\mathrm{HC}$ in theta band $(5-7 \mathrm{~Hz})$.

- Peak alpha frequency $(8-13 \mathrm{~Hz})$ correlated with a subjective fatigue rating.

- Peak frequency between 4-20 $\mathrm{Hz}$ correlated with theta/beta ratio and fatigue scores. *

Serial 7s:

- $\mathrm{ME}>\mathrm{HC}$ in theta band $(5-7 \mathrm{~Hz})$.

- $\mathrm{ME}<\mathrm{HC}$ in narrow alpha band $(9-11 \mathrm{~Hz})$

None measured subjects while performing handgrip contractions.
None

Basic personality inventory

Multidimensional Aptitude Battery (MAB-II)
$\mathrm{ME}<\mathrm{HCs}$ in maximum voluntary contraction force.*

$\mathrm{ME}>\mathrm{HCs}$ relative power in theta band, indicating higher cortical activity after moderate muscle exercise.

ME twins > healthy twins in delta $(2.0-3.5 \mathrm{~Hz})$ in left uncus and left parahippocampal gyrus.

ME twins > healthy twins in theta (4.0-7.5 Hz) in cingulate gyrus and right superior frontal gyrus.

Serial 7s data not reported.

Global source differences were found in both bands for all three conditions.

$\mathrm{ME}<\mathrm{HCs}$ in alpha during eyesclosed condition.

$\mathrm{ME}>\mathrm{HCs}$ in beta during spatial cognitive condition.

$\mathrm{ME}>\mathrm{HCs}$ in alpha in Broca's area during word-finding condition.

Spatial EEG patterns separated both groups at $83 \%$ classification rate in alpha band during word finding condition. 


\section{Table 1}

Case-control qEEG studies involving ME patients during wakefulness

\begin{tabular}{|c|c|c|c|c|}
\hline $\begin{array}{l}\text { Author } \\
\text { (Year) }\end{array}$ & $N$ & Investigation & $\begin{array}{l}\text { Behavioral } \\
\text { Measures }\end{array}$ & Significant Findings \\
\hline $\begin{array}{l}\text { Neu et al. } \\
(2011)\end{array}$ & $\begin{array}{l}15 \text { patients with } \\
\text { ME } \\
15 \text { untreated } \\
\text { sleep apnea- } \\
\text { hypopnea } \\
\text { syndrome } \\
\text { (SAHS) } \\
16 \text { healthy } \\
\text { controls }\end{array}$ & $\begin{array}{l}\text { Event-related potentials } \\
\text { recorded from Fz, Cz, } \\
\text { and Pz measuring } \\
\text { spectral theta and beta. } \\
\text { P300 assessment with } \\
\text { standard auditory } \\
\text { oddball paradigm } \\
\text { WAIS } \\
\text { Digit Span } \\
\text { Symbol span } \\
\text { Rey Auditory Verbal } \\
\text { Learning Test } \\
\text { Finger-tapping test }\end{array}$ & $\begin{array}{l}\text { Fatigue Severity } \\
\text { Scale (FSS) } \\
\text { Epworth Sleepiness } \\
\text { Scale (ESS) } \\
\text { Pittsburgh Sleep } \\
\text { Quality Index } \\
\text { (PSQ) } \\
\text { Beck Depression } \\
\text { Inventory } \\
13 \text { item short } \\
\text { form (BDI) } \\
\text { Hamilton Anxiety } \\
\text { Scale (HAS) } \\
\text { Hamilton } \\
\text { Depression Scale } \\
\text { (HDS) }\end{array}$ & $\begin{array}{l}\text { FSS: } M E>S A H S>H C \\
\text { ESS: } M E<S A H S>H C \\
\text { PSQ: } M E<S A H S>H C \\
\text { BDI: } M E>S A H S>H C \\
\text { HAS: } M E>S A H S>H C \\
\text { HDS: } M E>S A H S>H C \\
\text { WAIS: } M E>\text { SAHS }<\text { HC in both digit } \\
\text { span and symbol span } \\
\text { RAVLT: } M E>\text { SAHS }<\text { HC }\end{array}$ \\
\hline $\begin{array}{l}\text { Duffy, } \\
\text { McAnulty, } \\
\text { McCreary, } \\
\text { Cuchural, } \\
\text { and } \\
\text { Komaroff } \\
(2011)\end{array}$ & $\begin{array}{l}70 \text { patients with } \\
\text { ME } \\
24 \text { patients with } \\
\text { MDD } \\
148 \text { patients } \\
\text { with general } \\
\text { fatigue } \\
390 \text { healthy } \\
\text { controls }\end{array}$ & $\begin{array}{l}\text { EEG recordings to } \\
\text { measure coherence } \\
\text { during awake, alert } \\
\text { eyes-closed state }\end{array}$ & None & $\begin{array}{l}\text { EEG spectral coherence measures } \\
\text { distinguished ME patients from } \\
\text { HCs and MDD groups with nearly } \\
90 \% \text { accuracy. }\end{array}$ \\
\hline $\begin{array}{l}\text { M. L. Zinn } \\
\text { et al. (2014) }\end{array}$ & $\begin{array}{l}50 \text { patients } \\
50 \text { healthy } \\
\text { controls } \\
\text { matched by } \\
\text { age, gender, } \\
\text { educational } \\
\text { level. }\end{array}$ & $\begin{array}{l}\text { Used qEEG to measure } \\
\text { peak alpha frequency } \\
\text { (8-12 Hz) during an } \\
\text { eyes-closed resting } \\
\text { condition. }\end{array}$ & $\begin{array}{l}\text { Multidimensional } \\
\text { Fatigue } \\
\text { Inventory (MFI- } \\
\text { 20) } \\
\text { Fatigue Severity } \\
\quad \text { Scale (FSS) }\end{array}$ & $\begin{array}{l}\text { Found significantly reduced peak } \\
\text { alpha rhythms over } 56 \% \text { of cortex } \\
\text { in patients. } \\
\text { MFI-20, FSS were strongly } \\
\text { associated with peak alpha } \\
\text { frequency }(8-12 \mathrm{~Hz}) \text {. }\end{array}$ \\
\hline $\begin{array}{l}\text { M. A. Zinn } \\
\text { et al. (2014) }\end{array}$ & $\begin{array}{l}50 \text { patients } \\
50 \text { healthy } \\
\text { controls } \\
\text { matched by } \\
\text { age, gender, } \\
\text { educational } \\
\text { level. }\end{array}$ & $\begin{array}{l}\text { Used eLORETA to } \\
\text { measure current source } \\
\text { densities during an } \\
\text { eyes-closed resting } \\
\text { condition. }\end{array}$ & $\begin{array}{l}\text { Multidimensional } \\
\text { Fatigue } \\
\text { Inventory (MFI- } \\
\text { 20) } \\
\text { Fatigue Severity } \\
\text { Scale (FSS) }\end{array}$ & $\begin{array}{l}\text { ME > HC in delta }(1-3 \mathrm{~Hz}) \\
\text { predominately in bilateral } \\
\text { frontal/limbic regions. } \\
\mathrm{ME}<\mathrm{HC} \text { in beta }(19-21 \mathrm{~Hz}) \text { medially } \\
\text { in superior parietal lobule } \\
\text { (precuneus and sensorimotor } \\
\text { areas). } \\
\text { Maximal current densities for delta } \\
\text { band in left Broca's area predicted } \\
\text { by higher scores on the } \\
\text { Multidimensional Fatigue Inventory } \\
\text { (MFI-20), reduced motivation } \\
\text { subscale. } \\
\text { No associations found with the FSS. }\end{array}$ \\
\hline
\end{tabular}

${ }^{*} p<.01$ 
Importance of Cross-Frequency

Interactions, Vertical Brain Organization, and Arousal Systems

All perceptual, cognitive, and emotional processes in the brain arise from precisely coordinated timings (Rabinovich, Friston, et al., 2012) with a vertical organization of structures reflecting the phylogenic scale and forms of consciousness (including sleep/coma) beginning with the earliest reptilian structures (Thatcher \& John, 1977). Coupling between subcortical brain structures (e.g., brainstem), the limbic system (e.g., hippocampus) and the neocortex (e.g., dorsolateral prefrontal cortex) allows the brain to achieve multiple levels of adaptation critical for survival with subcortical structures exerting influence over the cortex, and vice-versa. A preponderance of slow-wave (delta, theta) activity cross-frequency coupled with faster rhythms (beta, gamma) is equally involved in the refinement of higher order information processing (Buzsáki \& Watson, 2012; Friston, Bastos, Pinotsis, \& Litvak, 2015). The nesting of brain rhythms reflects populations of neurons fluctuating in accordance to a hierarchical system modulated by ultraslow $(\sim 0.1 \mathrm{~Hz})$ frequencies (Buzsáki \& Watson, 2012). This effect demonstrates the interdependency of the rhythms; therefore, disruption in any frequency band could produce significant effects on the rhythms in other frequencies.

The correlation between lesions in white matter and increased delta waves was demonstrated by Gloor, Ball, and Schaul (1977). Bilateral lesions of the midbrain tegmentum produced bilateral delta activity in the cortex, while lesions in the reticular formation produced a gradual change in brain state with elevated delta rhythms, suggesting signaling depletion of a biochemical regulator. The authors explained that the lesions themselves did not produce delta activity; rather, the lesions interrupted important afferent connections to the cortex (deafferentation) from white matter, thalamus, hypothalamus, or brain stem leading to delta activity. Elevations in delta activity during the waking state have been a frequent finding in patients with acute phases of encephalitis and are correlated with infection severity, spatial involvement, arousal state, and metabolic factors (Schaul, Lueders, \& Sachdev, 1981; Westmoreland, 2005). African trypanosomiasis (sleeping sickness), which has characteristics similar to ME such as disturbance in sleep-wake cycles and excessive daytime drowsiness, is thought to arise from delta disruption during deep sleep stages (Westmoreland, 2005).
Delta is also implicated in disturbances of white matter and that is consistent with Purger, Gibson, and Monje (2015) who described in their review how varying levels of neuronal activity can result from subtle changes in myelin microstructure, perturbing neural function, resonances, and attunement of cognition and behavior. Similarly, patients with multiple sclerosis exhibit slow waves (delta) which tend to wax during symptom exacerbation periods and wane during remission while cognitive impairment in those patients is characterized by the extent and degree of slow oscillations found (Westmoreland, 2005).

The earliest clinical correlates of brain pathogenesis are often seen with subtle, fluctuating levels of attention and arousal (Ropper \& Samuels, 2009) and concomitant alterations in consciousness are then likely to follow with intracranial disease (e.g., infectious, inflammatory, neoplastic, vascular, and traumatic etiologies; Niedermeyer \& Lopes da Silva, 2005). In analyzing patients with deep brain lesions, Luria (1980) noticed that changes in specialized higher cortical processes remained intact, and he observed that the primary symptoms manifested by patients were generalized decreases in "cortical tone" accompanied by a substantial degree of slowness and proneness to fatigue, affecting all the spheres of their activity. Another feature of Luria's patients was large fluctuations in symptom severity; during some hours or days the patients' symptoms grew worse, while at other hours or days the same symptoms took on a milder form. Moreover, the changes described by Luria are remarkably characteristic of neurological illnesses involving central fatigue (Chaudhuri \& Behan, 2004) with striking similarity to ME. Neurocognitive functioning depends on an intact AAS in promoting effective transmission across many thalamocortical, cortiobasal-thalamic, and cortico-cortical circuits operating continuously during sleep and wakefulness in accordance with circadian rhythms (Heyder, Suchan, \& Daum, 2004; Wright et al., 2012). The hierarchical cross-frequency interactions are mediated by reticulothalamic and monoamine projections (e.g., acetylcholine in the basal forebrain, serotonin and norepinephrine in the pons, histamine and orexin in the hypothalamus, dopamine and acetylcholine in the midbrain) which serve to dampen the slower frequencies (delta), reduce the number of refractory neurons (more neurons available for allocation), and sustain the generalized maintenance of alert levels of consciousness (see Figure 1). 


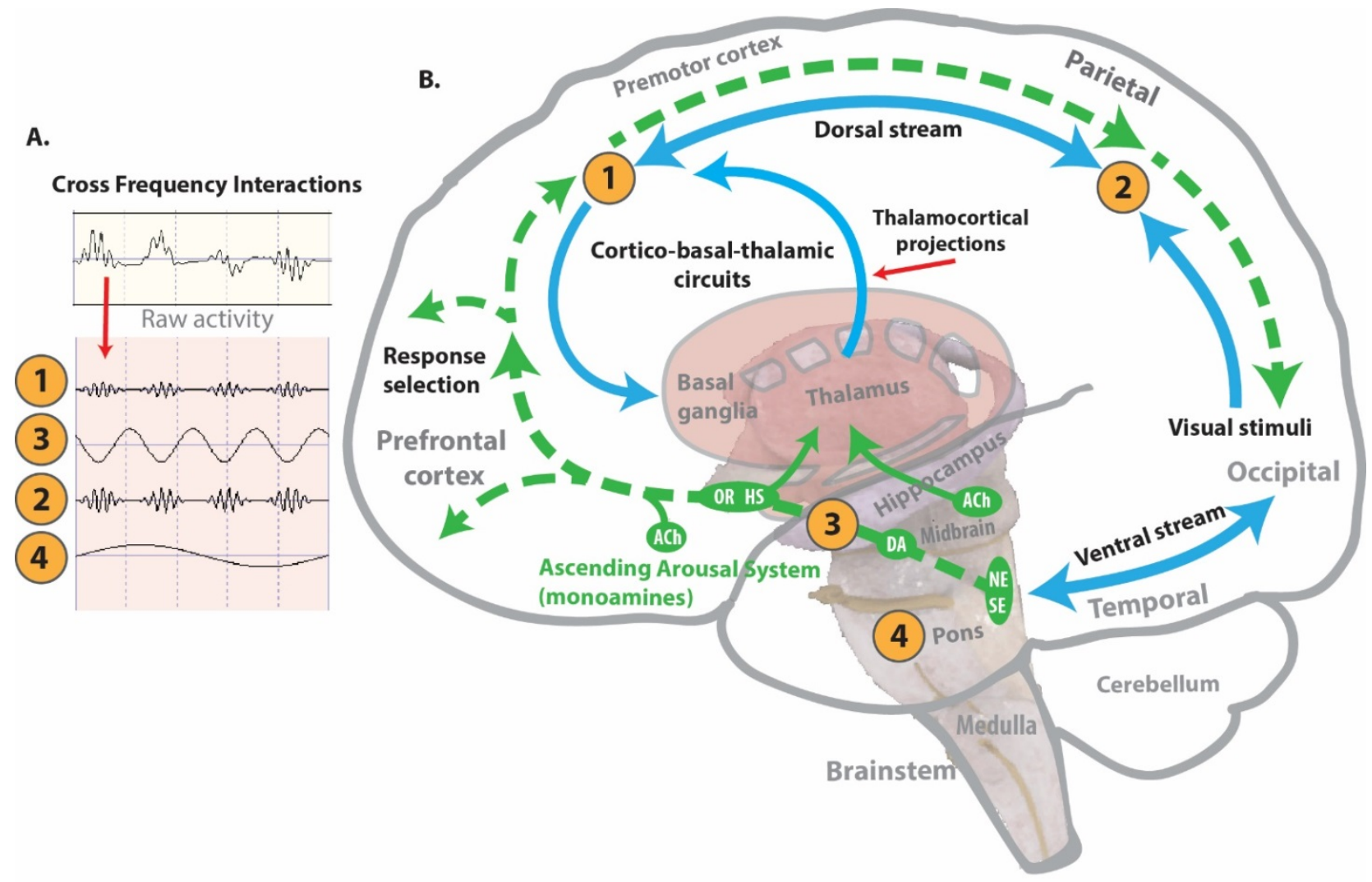

Figure 1. Neurocognitive impairment in ME model based on vertical brain organization, ascending arousal system (AAS), and cross-frequency interactions involved in the metastable dynamic flow of information in higher cortical function [adapted from Rabinovich, Afraimovich, et al. (2012), Stratton and Wiles (2015), Thatcher and John (1977), Wright et al. (2012)]. A) Crossfrequency interactions (coupling) showing gamma, theta, and delta frequencies are woven together by phase relationships occurring spontaneously across different brain regions at multiple hierarchical levels. If dysfunction exists in any of the sites (e.g., increased delta), the temporal "fabric" changes accordingly. Inefficient cross-frequency coupling within the raw EEG signal can be separated and analyzed by qEEG and electrical neuroimaging methods (Pinal, Zurrón, Díaz, \& Sauseng, 2015). B) Brain function at the systems level which is modeled on the vertical organization of the brain circuits in millisecond timings and cycling of oscillatory rhythms (Tristan et al., 2014), accounting for the primary role of arousal promoting nuclei in the brainstem, for example, site 4 (pons) in promoting the encoding and processing of sensory information (e.g., visual stimuli in occipital lobe) influencing the cross-coupled signaling in the dorsal stream of information flow between gamma activity in site 1 (parietal) and site 2 (premotor) coupled with theta rhythms in site 3 (memories recalled by the hippocampus) mediated by prefrontal cortex (filtering out irrelevant stimuli, context-dependent response selection) and cortico-basal-thalamic circuits (anticipatory information), ultimately giving rise to behavior, emotion, and cognition (Fuster, 2009; Rabinovich, Afraimovich, et al., 2012; Stratton \& Wiles, 2015). This general hypothesis states that the AAS (dashed green lines) regulates the capacity for neuronal excitability within the information streams (blue arrows) perpetuated by local and long-distance connections within and between networks. Characterizing the metastable dynamics in the brain may be crucial in understanding neurocognitive impairment, particularly in ME; that is, disruptions in signaling at any point (e.g., red arrow pointing to thalamocortical afferent pathways) underpinning information processing deficits and influencing pyramidal neuronal populations in the cortex visible in the qEEG (McCormick \& Bal, 1997; Stratton \& Wiles, 2015). This model calls for a deeper understanding of dysregulation in the central nervous system in patients; that is, how communication by way of network properties and arousal affects the quality and quantity of the mental representations in the cortex at any given moment in time (Varela, 2014). Within this model, the homeostatic balance of efficient ongoing processing, in turn, produces increased responsiveness of cortical networks that depend on intact subcortical structures. Accordingly, mismatched timings may be indexed by underlying phase mechanisms (Thatcher, North, \& Biver, 2014) associated with a variety of conditions such as multiple sclerosis (Yao et al., 2012), autism (Thatcher et al., 2009), Alzheimer's disease (Xu et al., 2008) and short-term memory decline (Pinal et al., 2015). Abbreviations: acetylcholine (ACh), dopamine (DA), histamine (HS), orexin (OR), norepinephrine (NE), serotonin (SE). 
The role of brain rhythms and vertical brain organization affecting behavioral performance with time-evolving variability in brain states may be of prime importance to ME. The ability to flexibly switch and maintain brain states to mandate a given performance level is critical to shifting environmental demands (Tang et al., 2012) and ME is known for supporting derangements in set shifting. Delta is associated with potassium $(\mathrm{K}+)$ conductance of the membrane potential which can be readily abolished by monoamine-producing nuclei in the pons and midbrain reticular formation (e.g., acetylcholine or norepinephrine) for maintenance of normal consciousness (Steriade, 2006). Severe damage to the midbrain reticular formation produces coma whereby lack of sustained input from the neocortex precludes all function (Nolte, 2009). Cortical arousal becomes initiated by the cholinergic basal forebrain which plays a key role in blocking $\mathrm{K}+$ conductance (Metherate \& Ashe, 1993) and strong cholinergic activity during REM and wakefulness is mainly responsible for depolarizing thalamocortical neurons to suppress the occurrence of delta oscillations and diminished excitation in the cortex (McCormick \& Bal, 1997). Furthermore, the thalamic neurons projecting to the well-defined areas of the cortex operate in a different manner, and they have essentially two physiological modes: tonic mode and burst mode. Delta rhythms produced by these particular neurons switch their operating mode from tonic mode to burst mode where hyperpolarization of neurons is below the threshold for the tonic mode, thus interrupting normal relay of information back to the neocortex (Sherman \& Guillery, 1996). During burst mode, the thalamocortical neurons are operating with increased calcium $\left(\mathrm{Ca}^{+2}\right)$ influx, making them behave differently; they are more prone to fire in an all-or-none fashion (Zhan, Cox, Rinzel, \& Sherman, 1999). This type of irregular transmission produces a type of hyper-responsivity which negates the proper functioning of cortical systems (Elson et al., 1999; Steriade \& Paré, 2006). The instability might be semantic in that the remaining information that gets forwarded to the neocortex is compromised, disrupting the ability of neocortical systems to perform their task of discrimination and refinement of incoming sensory information. Likewise, the instability could be produced temporally where the message is the same but the order has been randomized or the tempo of information is too erratic and, with regard to attention, making it difficult to process relevant information (Tristan et al., 2014).

\section{Using EEG Coherence and Phase Metrics to Investigate ME Neurocognitive Impairment}

Using time-dependent EEG metrics such as coherence and phase within brain rhythms could form a new conceptual basis of studying neurocognitive impairment in patients with ME. EEG coherence was used by Duffy et al. (2011) as a way of distinguishing ME from depression and healthy control groups. Coherence is the most widely used measure which examines similarity between two cortical regions as well as provides a robust measure of white matter maturation/disease (Nunez, Srinivasan, \& Fields, 2014). Coherence looks at phase differences to directly measure the timing of neural activity to elucidate the coordination of action potentials (Klimesch et al., 2008) between any two brain areas and infer a functional relationship is likely happening (phase coupling; Buzsáki \& Watson, 2012). Areas with higher coherence are referred to as having increased phase consistency whereby phase differences are clustering very close together over time. However, if the phase differences are fairly scattered over time, there is an inconsistency of phase differences, and those neurons become suppressed. This suggests a fundamental mechanism for selection of neurons: neurons are very likely to fire together when their phases are coupled and the firing threshold is lower, but they become suppressed when their phases are decoupled due to lack of entrainment (decoupling; Hughes et al., 2004). More importantly, high coherence measures demonstrate that neurons are delivering large quantities of neurotransmitters, which rapidly turn neurons on/off, and the neuromodulators, which modulate synaptic transmission and RNA signaling (Kandel, Schwartz, Jessell, Siegelbaum, \& Hudspeth, 2012). Findings of intracranial studies show functional coupling in the frontal cortex and connected areas is essentially linked to fundamental memory processes (Johnson \& Knight, 2015). Furthermore, a coupling of EEG signals, in addition to power, has been shown to modulate temporal attention intervals contributing to task performance and reaction speed (Stefanics et al., 2010).

We can understand coherence more comprehensively by examining control processes for how the information is being encoded and packaged through analysis of phase reset mechanisms and their constituent subcomponents of phase shift and phase-lock duration. Phase shift and phase lock are fundamental brain mechanisms continually in flux at various frequencies and across nodes of networks during the execution of any behavioral or cognitive 
task. According to Canavier (2015), phase-reset performs several functions to represent our thoughts, feelings, and actions: 1) phase alignment to specific reference points, 2) time windows for encoding and decoding, and 3) coordination between mutually connected, phase coupled, brain regions. Recent evidence demonstrates the processes of phase reset on human cognition, especially in clinical disorders (Frey, Ruhnau, \& Weisz, 2015). The homeostatic balance of switching dynamics between phase shifting and phase locking and of rhythm patterns has been related to normal brain function, and instabilities have been implicated in pathological conditions such as autism (Thatcher et al., 2009), epilepsy (Chavez, Le Van Quyen, Navarro, Baulac, \& Martinerie, 2003; Le Van Quyen, Martinerie, Navarro, Baulac, \& Varela, 2001), Alzheimer's disease (Stam et al., 2002), and traumatic brain injury (Sponheim et al., 2011).

At any given moment, millions of neurons are briefly synchronized (phase locked) across domains or networks within milliseconds and then released (phase shift), and this process happens continually with different neurons being involved (Thatcher, 2012). Phase shift refers to the recruitment process of allocating all available neurons for performing a given function and typically varies between 40 and 80 milliseconds in length, and it has been shown to positively correlate with intelligence (Thatcher, North, \& Biver, 2008). Phase lock refers to the synchronization of phase-shifted neurons selected for mediating a given function over a sustained period of time, usually between 100 and 600 milliseconds. For example, phase-locking periods of $100 \mathrm{~ms}$ in the alpha band in the auditory cortex was recently shown to modulate visual perception in the occipital lobe (Romei, Gross, \& Thut, 2012). Longer phase-lock periods were found to be inversely correlated with intelligence due to the brief increase in committed neurons which creates a momentary reduction in neurons available for other phase shifts (Thatcher et al., 2008). It is possible to apply this phase reset model to understanding the inner workings of the brain in ME. If patients were shown to have a higher rate of phase resets than normal in the high beta/gamma range, the information transfer within neocortical local circuits might be happening too quickly. Looking further at phase shift and phase-lock duration, if both of these processes appeared to be significantly shorter, that might further suggest there are fewer neuronal resources allocated in ME for subsequent phase-lock periods. This could lead to inefficiency as a function of time and, if both periods of phase shift/lock durations were too short, that might contribute to an increased rate of phase reset. Also, with phase-locking periods being too brief, that would be consistent with the associated lower rate of information processing and reaction times found in the ME literature.

To create a better understanding, however, it becomes necessary to describe the aberrant coherence and phase within the nodes of largescale networks dedicated to maintaining higher cognitive functions affecting daily living (e.g., spatial attention, salience recognition, autobiographical memory, sensation and movement, language and sound). Cooperative sequencing and millisecond interactions of dynamic functional systems in the brain (interconnected groupings) are involved in overall function at any given moment of time and can be interrupted by a number of different types of neurological derangements (Menon, 2011; Sporns, 2013). In addition to hierarchical levels of brain rhythms, there are also hierarchical levels of nodes and hub constituents of brain networks. Given their central importance and susceptibility to failure in many clinical disorders (Crossley et al., 2014), coherence and phase analysis within hubs could be another tool for measuring the functional integrity of their connections. The degree to which dysregulation within the nodes or hubs of a given network is found could serve as an index for the inefficiency of information processing and greater energy expenditure, particularly in the compensatory nodes; the dysregulated nodes and hubs continue to function while other nodes attempt to compensate for the information processing deficits, producing greater inefficiency. More powerful and versatile data-driven approaches using independent component analysis to characterize frequencies and spatial correlations simultaneously might yield new insights identifying cortico-cortical, cross-frequency interactions, which can account for compensatory mechanisms (Calhoun, Liu, \& Adali, 2009; PascualMarqui et al., 2011). Unique to exploring the realm of dynamic connectivity electrical neuroimaging can capture co-varying correlations of regions, including connection strength, direction, and spectral characteristics, from intracranial electric signals. Dynamic connectivity has recently been shown to offer more reliability and sensitivity for measuring network properties in Parkinson's disease (Madhyastha, Askren, Boord, \& Grabowski, 2015). Direct paths of effective information flow can be assessed using newly established metrics such as isolated effective coherence (Pascual-Marqui et al., 2014) and phase slope index (Nolte \& Müller, 2010; Nolte et al., 2008), which can be used in causal connectivity modeling to describe transmission of preferential oscillations between nodes. In 
summary, using electrical neuroimaging methods may help identify dysregulated nodes within largescale brain networks and dynamic connectivity models which could better characterize the nature and extent of neurocognitive impairment in ME.

\section{Clinical Interpretation of Dysregulated Networks in ME}

Clinical interpretation ultimately rests upon linking the patient's symptoms to dysregulated nodes and hubs of large-scale brain systems (Thatcher, 2012). These large distributed networks were mapped through numerous neuroimaging experiments showing areas of endogenous brain activity that were highly correlated and ultimately referred to as resting-state networks (Allen et al., 2011; Fox, Zhang, Snyder, \& Raichle, 2009; Raichle, 2011). To gain a deeper understanding of connectivity influences of brain disease on cognitive processing, the assessment of neuropsychological symptoms in patients can be linked to specific alternations in the resting-state networks. Initial steps for investigating neurocognitive impairment in ME could begin with the default-mode network (Raichle et al., 2001). The default-mode network is the first resting-state network to be identified and has been a robust finding in the literature (Raichle, 2011; Raichle et al., 2001). The nodes identified in this network include the medial prefrontal cortex, posterior cingulate/precuneus, and the bilateral temporalparietal junction. Collectively, these nodes are jointly active during passive moments-while one is recalling past events, ruminating, self-monitoringbut they deactivate during initiation of a goaldirected task (Buckner, 2012). Cognitive symptoms produced by a failure within this network would involve decreased attention, mentalizing, decisionmaking, self-referential thought, and self-recognition. The default-mode network has been implicated in symptoms of a variety of neurocognitive disorders such as Alzheimer's disease (Greicius, Srivastava, Reiss, \& Menon, 2004), Parkinson's disease (van Eimeren, Monchi, Ballanger, \& Strafella, 2009), traumatic brain injury (Bonnelle et al., 2011), multiple sclerosis (Zhou et al., 2014), epilepsy (Haneef, Lenartowicz, Yeh, Engel, \& Stern, 2014), autism (Jann et al., 2015). In ME, the relative interactions between nodes of the default-mode network could be examined using phase and coherence metrics within LORETA to explore temporal dynamics within a graph theoretical framework; the connectivity of edges between dysfunctional nodes identified as hyper/hypo connected according to EEG frequency band (Pascual-Marqui et al., 2011). To show how it relates to fatigue, the results could then be regressed against scores on neuropsychological tests and subjective behavior measures. These procedures could be then repeated for testing the integrity of other resting-state networks (e.g., salience network, the executive control network, dorsal/ventral attention networks, visual network, sensorimotor network, and auditory networks; (Raichle, 2011) to potentially reveal highly essential clues specific to ME neurocognitive impairment. Specific patterns that are identified using the approach will likely serve as potential targets for treatment (e.g., EEG biofeedback).

\section{Multi-modal EEG Integration}

One of the ultimate goals of neuroscience is to find ways of bringing together imaging modalities for the best clinical outcome. Through an integration of neuroimaging (e.g., EEG/MEG with MRI and $\mathrm{fMRI}$ techniques), we take advantage of what each modality has to offer to increase our understanding of adverse conditions in the brain (Liu, Ding, \& He, 2006). Electrical neuroimaging findings can be coregistered with respect to all these imaging modalities and integrative EEG studies thus far are yielding important noninvasive insights regarding state changes in functional brain architecture (Michel \& Murray, 2012). Moreover, DTI modeling of connections in the brain infrastructure forms the basis for understanding and cross-validation of the electric neuroimaging results (Hagmann et al., 2008; Thatcher, North, \& Biver, 2012). Finally, combining other modalities is one way to expand our novel approaches for selection of new treatments and differential diagnosis for patients with $M E$ in particular.

\section{Conclusion}

Neural dynamics is fundamental for all types of brain processes. Targeting neural dynamics in real time remains attractive but currently poses a significant challenge to researchers and clinicians, particularly in ME. Progress in developing better methods to assess neurocognitive impairment has been limited, possibly due to the lack of newer methods developed and perceived redundancy between animated and static neuroimaging methods. The potential to assess, and possibly treat, neurocognitive problems in $\mathrm{ME}$ is evident as per the quantitative EEG methods and preliminary data presented in this article.

An important area of future research is to better understand the manner in which neurons communicate through networks and how that process is truncated in disease. Although it is fairly evident that central nervous system connectivity is a 
likely candidate, much more needs to be known about its effect upon neurocognitive dysfunction in $\mathrm{ME}$ in order to develop new concepts for the understanding, diagnosis, and treatment of patients.

\section{Conflict of Interest}

The authors confirm that this article content has no competing interest.

Our thanks to Linda Clark for generously providing us financial support.

\section{References}

Abbey, S. E., \& Garfinkel, P. E. (1991). Neurasthenia and chronic fatigue syndrome: the role of culture in the making of a diagnosis. The American Journal of Psychiatry, 148(12), 1638-1646.

Afari, N., \& Buchwald, D. (2003). Chronic fatigue syndrome: a review. The American Journal of Psychiatry, 160(2), 221-236.

Allen, E. A., Erhardt, E. B., Damaraju, E., Gruner, W., Segall, J. M., Silva, R. F., ... Calhoun, V. D. (2011). A baseline for the multivariate comparison of resting-state networks. Frontiers in Systems Neuroscience, 5, 2. http://dx.doi.org/10.3389 Ifnsys.2011.00002

Angelakis, E., \& Lubar, J. F. (2002). Quantitative electroencephalographic amplitude measures in young adults during reading tasks and rest. Journal of Neurotherapy, 6(2), 5-19. http://dx.doi.org/10.1300/J184v06n02 03

Attree, E. A., Arroll, M. A., Dancey, C. P., Griffith, C., \& Bansal, A. S. (2014). Psychosocial factors involved in memory and cognitive failures in people with myalgic encephalomyelitis/chronic fatigue syndrome. Psychology Research and Behavior Management, 7, 67-76. http://dx.doi.org/10.2147/prbm.s50645

Babiloni, C., Binetti, G., Cassetta, E., Cerboneschi, D., Dal Forno, G., Del Percio, C., ... Rossini, P. M. (2004). Mapping distributed sources of cortical rhythms in mild Alzheimer's disease. A multicentric EEG study. Neurolmage, 22(1), 5767. http://dx.doi.org/10.1016/j.neuroimage.2003.09.028

Babiloni, C., Carducci, F., Lizio, R., Vecchio, F., Baglieri, A., Bernardini, S., ... Frisoni, G. B. (2013). Resting state cortical electroencephalographic rhythms are related to gray matter volume in subjects with mild cognitive impairment and Alzheimer's disease. Human Brain Mapping, 34(6), 14271446. http://dx.doi.org/10.1002/hbm.22005

Babiloni, C., Cassetta, E., Dal Forno, G., Del Percio, C., Ferreri, F., Ferri, R., ... Rossini, P. M. (2006). Donepezil effects on sources of cortical rhythms in mild Alzheimer's disease: Responders vs. Non-Responders. Neurolmage, 31(4), 16501665. http://dx.doi.org/10.1016/j.neuroimage.2006.02.015

Babiloni, C., De Pandis, M. F., Vecchio, F., Buffo, P., Sorpresi, F., Frisoni, G. B., \& Rossini, P. M. (2011). Cortical sources of resting state electroencephalographic rhythms in Parkinson's disease related dementia and Alzheimer's disease. Clinical Neurophysiology, 122(12), 2355-2364. http://dx.doi.org /10.1016/j.clinph.2011.03.029

Babiloni, C., Del Percio, C., Lizio, R., Marzano, N., Infarinato, F., Soricelli, A., ... Rossini, P. M. (2014). Cortical sources of resting state electroencephalographic alpha rhythms deteriorate across time in subjects with amnesic mild cognitive impairment. Neurobiology of Aging, 35(1), 130-142. http://dx.doi.org/10.1016/j.neurobiolaging.2013.06.019

Babiloni, C., Frisoni, G., Steriade, M., Bresciani, L., Binetti, G., Del Percio, C., ... Rossini, P. M. (2006). Frontal white matter volume and delta EEG sources negatively correlate in awake subjects with mild cognitive impairment and Alzheimer's disease. Clinical Neurophysiology, 117(5), 1113-1129. http://dx.doi.org/10.1016/j.clinph.2006.01.020

Babiloni, C., Pistoia, F., Sarà, M., Vecchio, F., Buffo, P., Conson, M., ... Rossini, P. M. (2010). Resting state eyes-closed cortical rhythms in patients with locked-in-syndrome: an EEG study. Clinical Neurophysiology, 121(11), 1816-1824. http://dx.doi.org/10.1016/j.clinph.2010.04.027

Barnden, L. R., Crouch, B., Kwiatek, R., Burnet, R., \& Del Fante, P. (2015). Evidence in chronic fatigue syndrome for severitydependent upregulation of prefrontal myelination that is independent of anxiety and depression. NMR in Biomedicine, 28(3), 404-413. http://dx.doi.org/10.1002/nbm.3261

Barnden, L. R., Crouch, B., Kwiatek, R., Burnet, R., Mernone, A., Chryssidis, S., ... Del Fante, P. (2011). A brain MRI study of chronic fatigue syndrome: evidence of brainstem dysfunction and altered homeostasis. NMR In Biomedicine, 24(10), 13021312. http://dx.doi.org/10.1002/nbm.1692

Bazhenov, M., \& Makeig, S. (2012). Multiscale electroencephalographic dynamics and brain function. In M. I. Rabinovich, K. J. Friston \& P. Varona (Eds.), Principles of Brain Dynamics: Global State Interactions (pp. 165-181). Cambridge, MA: The MIT Press.

Besenyei, M., Varga, E., Fekete, I., Puskás, S., Hollódy, K., Fogarasi, A., ... Clemens, B. (2012). EEG background activity is abnormal in the temporal and inferior parietal cortex in benign rolandic epilepsy of childhood: a LORETA study. Epilepsy Research, 98(1), 44-49. http://dx.doi.org/10.1016 /j.eplepsyres.2011.08.013

Billiot, K. M., Budzynski, T. H., \& Andrasik, F. (1997). EEG Patterns and Chronic Fatigue Syndrome. Journal of Neurotherapy, 2(2), 20-30. http://dx.doi.org/10.1300 IJ184v02n02_04

Biswal, B., Kunwar, P., \& Natelson, B. H. (2011). Cerebral blood flow is reduced in chronic fatigue syndrome as assessed by arterial spin labeling. Journal of the Neurological Sciences, 301(1-2), 9-11. http://dx.doi.org/10.1016/j.jns.2010.11.018

Bonnelle, V., Leech, R., Kinnunen, K. M., Ham, T. E., Beckmann, C. F., De Boissezon, X., ... Sharp, D. J. (2011). Default mode network connectivity predicts sustained attention deficits after traumatic brain injury. The Journal of Neuroscience, 31(38), 13442-13451. http://dx.doi.org/10.1523/jneurosci.116311.2011

Bredt, D. S., \& Nicoll, R. A. (2003). AMPA receptor trafficking at excitatory synapses. Neuron, 40(2), 361-379.

Buckner, R. L. (2012). The serendipitous discovery of the brain's default network. Neurolmage, 62(2), 1137-1145. http://dx.doi.org/10.1016/j.neuroimage.2011.10.035

Bullmore, E., \& Sporns, O. (2012). The economy of brain network organization. Nature Reviews Neuroscience, 13(5), 336-349. http://dx.doi.org/10.1038/nrn3214

Buzsáki, G. (2006). Rhythms of the Brain. New York, NY: Oxford University Press.

Buzsáki, G., \& Watson, B. O. (2012). Brain rhythms and neural syntax: implications for efficient coding of cognitive content and neuropsychiatric disease. Dialogues in Clinical Neuroscience, 14(4), 345-367.

Cairns, R., \& Hotopf, M. (2005). A systematic review describing the prognosis of chronic fatigue syndrome. Occupational Medicine, 55(1), 20-31. http://dx.doi.org/10.1093/occmed /kqi013

Calhoun, V. D., Liu, J., \& Adali, T. (2009). A review of group ICA for fMRI data and ICA for joint inference of imaging, genetic, and ERP data. Neurolmage, 45(Suppl. 1), S163-S172. http://dx.doi.org/10.1016/j.neuroimage.2008.10.057

Canavier, C. C. (2015). Phase-resetting as a tool of information transmission. Current Opinion in Neurobiology, 31, 206-213. http://dx.doi.org/10.1016/j.conb.2014.12.003 
Canuet, L., Ishii, R., Pascual-Marqui, R. D., Iwase, M., Kurimoto, R., Aoki, Y., ... Takeda, M. (2011). Resting-state EEG source localization and functional connectivity in schizophrenia-like psychosis of epilepsy. PloS ONE, 6(11), e27863. http://dx.doi.org/10.1371/journal.pone.0027863

Canuet, L., Tellado, I., Couceiro, V., Fraile, C., Fernandez-Novoa, L., Ishii, R., ... Cacabelos, R. (2012). Resting-state network disruption and APOE genotype in Alzheimer's disease: a lagged functional connectivity study. PloS ONE, 7(9), e46289. http://dx.doi.org/10.1371/journal.pone.0046289

Capuron, L., Welberg, L., Heim, C., Wagner, D., Solomon, L., Papanicolaou, D. A., ... Reeves, W. C. (2006). Cognitive dysfunction relates to subjective report of mental fatigue in patients with chronic fatigue syndrome. Neuropsychopharmacology, 31(8), 1777-1784. http://dx.doi.org/10.1038/sj.npp.1301005

Caseras, X., Mataix-Cols, D., Giampietro, V., Rimes, K. A., Brammer, M., Zelaya, F., ... Godfrey, E. L. (2006). Probing the working memory system in chronic fatigue syndrome: a functional magnetic resonance imaging study using the $n$ back task. Psychosomatic Medicine, 68(6), 947-955. http://dx.doi.org/10.1097/01.psy.0000242770.50979.5f

Caseras, X., Mataix-Cols, D., Rimes, K. A., Giampietro, V., Brammer, M., Zelaya, F., ... Godfrey, E. (2008). The neural correlates of fatigue: an exploratory imaginal fatigue provocation study in chronic fatigue syndrome. Psychological Medicine, 38(7), 941-951. http://dx.doi.org/10.1017 /s0033291708003450

Catani, M. (2011). John Hughlings Jackson and the clinicoanatomical correlation method. Cortex, 47(8), 905-907. http://dx.doi.org/10.1016/j.cortex.2011.06.002

Catani, M., Bodi, I., \& Dell'Acqua, F. (2012). Comment on "The geometric structure of the brain fiber pathways." Science, 337(6102), 1605. http://dx.doi.org/10.1126/science.1223425

Catani, M., Dell'Acqua, F., Bizzi, A., Forkel, S. J., Williams, S. C., Simmons, A., ... Thiebaut de Schotten, M. (2012). Beyond cortical localization in clinico-anatomical correlation. Cortex, 48(10), 1262-1287. http://dx.doi.org/10.1016 /j.cortex.2012.07.001

Chaudhuri, A., \& Behan, P. O. (2004). Fatigue in neurological

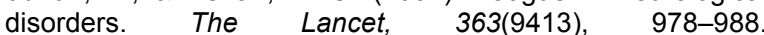
http://dx.doi.org/10.1016/S0140-6736(04)15794-2

Chavez, M., Le Van Quyen, M., Navarro, V., Baulac, M., \& Martinerie, J. (2003). Spatio-temporal dynamics prior to neocortical seizures: amplitude versus phase couplings. IEEE Transactions on Biomedical Engineering, 50(5), 571-583. http://dx.doi.org/10.1109/tbme.2003.810696

Chen, A. C. N., Feng, W., Zhao, H., Yin, Y., \& Wang, P. (2008). EEG default mode network in the human brain: spectra regional field powers. Neurolmage, 41(2), 561-574. http://dx.doi.org/10.1016/j.neuroimage.2007.12.064

Cho, H. J., Skowera, A., Cleare, A., \& Wessely, S. (2006). Chronic fatigue syndrome: an update focusing on phenomenology and pathophysiology. Current Opinion in Psychiatry, 19(1), 67-73. http://dx.doi.org/10.1097 101.yco.0000194370.40062.b0

Christley, Y., Duffy, T., Everall, I. P., \& Martin, C. R. (2013). The neuropsychiatric and neuropsychological features of chronic fatigue syndrome: revisiting the enigma. Current Psychiatry Reports, 15(4), 353. http://dx.doi.org/10.1007/s11920-0130353-8

Christodoulou, C., DeLuca, J., Lange, G., Johnson, S. K., Sisto, S. A., Korn, L., \& Natelson, B. H. (1998). Relation between neuropsychological impairment and functional disability in patients with chronic fatigue syndrome. Journal of Neurology, Neurosurgery, and Psychiatry, 64(4), 431-434.

Cleare, A. J., Messa, C., Rabiner, E. A., \& Grasby, P. M. (2005). Brain $5-\mathrm{HT}_{1 \mathrm{~A}}$ receptor binding in chronic fatigue syndrome measured using positron emission tomography and $\left[{ }^{11}\right.$ C]WAY-100635. Biological Psychiatry, 57(3), 239-246. http://dx.doi.org/10.1016/j.biopsych.2004.10.031

Clemens, B., Bánk, J., Piros, P., Bessenyei, M., Vető, S., Tóth, M., \& Kondákor, I. (2008). Three-dimensional localization of abnormal EEG activity in migraine: a low resolution electromagnetic tomography (LORETA) study of migraine patients in the pain-free interval. Brain Topography, 21(1), 36-42. http://dx.doi.org/10.1007/s10548-008-0061-6

Clemens, B., Bessenyei, M., Fekete, I., Puskás, S., Kondákor, I., Tóth, M., \& Hollódy, K. (2010). Theta EEG source localization using LORETA in partial epilepsy patients with and without medication. Clinical Neurophysiology, 121(6), 848-858. http://dx.doi.org/10.1016/j.clinph.2010.01.020

Cockshell, S. J., \& Mathias, J. L. (2010). Cognitive functioning in chronic fatigue syndrome: A meta-analysis. Psychological Medicine, 40(8), 1253-1267. http://dx.doi.org/10.1017 /s0033291709992054

Cockshell, S. J., \& Mathias, J. L. (2012). Test effort in persons with Chronic Fatigue Syndrome when assessed using the Validity Indicator Profile. Journal of Clinical and Experimental Neuropsychology, 34(7), 679-687. http://dx.doi.org/10.1080 /13803395.2012.668176

Cockshell, S. J., \& Mathias, J. L. (2014). Cognitive functioning in people with chronic fatigue syndrome: a comparison between subjective and objective measures. Neuropsychology, 28(3), 394-405. http://dx.doi.org/10.1037/neu0000025

Cook, D. B., O'Connor, P. J., Lange, G., \& Steffener, J. (2007). Functional neuroimaging correlates of mental fatigue induced by cognition among chronic fatigue syndrome patients and controls. Neurolmage, 36(1), 108-122. http://dx.doi.org /10.1016/j.neuroimage.2007.02.033

Cope, H., \& David, A. S. (1996). Neuroimaging in chronic fatigue syndrome. Journal of Neurology, Neurosurgery, and Psychiatry, 60(5), 471-473.

Cope, H., Pernet, A., Kendall, B., \& David, A. (1995). Cognitive functioning and magnetic resonance imaging in chronic fatigue. The British Journal of Psychiatry, 167(1), 86-94.

Costa, D. C., Tannock, C., \& Brostoff, J. (1995). Brainstem perfusion is impaired in chronic fatigue syndrome. Quarterly Journal of Medicine, 88(11), 767-773.

Crossley, N. A., Mechelli, A., Scott, J., Carletti, F., Fox, P. T., McGuire, P., \& Bullmore, E. T. (2014). The hubs of the human connectome are generally implicated in the anatomy of brain disorders. Brain, 137(8), 2382-2395. http://dx.doi.org/10.1093 /brain/awu132

de Hoz, L., \& Simons, M. (2015). The emerging functions of oligodendrocytes in regulating neuronal network behaviour. BioEssays, 37(1), 60-69. http://dx.doi.org/10.1002 /bies.201400127

de Lange, F. P., Kalkman, J. S. , Bleijenberg, G., Hagoort, P., van der Meer, J. W. M., \& Toni, I. (2005). Gray matter volume reduction in the chronic fatigue syndrome. Neurolmage, 26(3), 777-781. http://dx.doi.org/10.1016 /j.neuroimage.2005.02.037

de Lange, F. P., Kalkman, J. S., Bleijenberg, G., Hagoort, P., van der Werf, S. P., van der Meer, J. W. M., \& Toni, I. (2004). Neural correlates of the chronic fatigue syndrome-An fMRI study. Brain, 127(9), 1948-1957. http://dx.doi.org/10.1093 /brain/awh225

de Lange, F. P., Koers, A., Kalkman, J. S., Bleijenberg, G., Hagoort, P., van der Meer, J. W. M., \& Toni, I. (2008). Increase in prefrontal cortical volume following cognitive behavioural therapy in patients with chronic fatigue syndrome. Brain, 131(8), 2172-2180. http://dx.doi.org/10.1093/brain lawn140

Deco, G., Jirsa, V., \& Friston, K. J. (2012). The dynamical structural basis of brain activity. In M. I. Rabinovich, K. Friston \& P. Varona (Eds.), Principles of Brain Dynamics: Global State Interactions (pp. 1-23). Cambridge, MA: The MIT Press. 
DeLuca, J. (Ed.). (2005). Fatigue as a Window to the Brain. Cambridge, MA: The MIT Press.

DeLuca, J., Christodoulou, C., Diamond, B. J., Rosenstein, E. D., Kramer, N., \& Natelson, B. H. (2004). Working memory deficits in chronic fatigue syndrome: differentiating between speed and accuracy of information processing. Journal of the International Neuropsychological Society, 10(1), 101-109. http://dx.doi.org/10.1017/s1355617704101124

DeLuca, J., Genova, H. M., Capili, E. J., \& Wylie, G. R. (2009). Functional neuroimaging of fatigue. Physical Medicine and Rehabilitation Clinics of North America, 20(2), 325-337. http://dx.doi.org/10.1016/j.pmr.2008.12.007

Dickinson, C. J. (1997). Chronic fatigue syndrome-aetiological aspects. European Journal of Clinical Investigation, 27(4), 257-267. 2362.1997.1120664.x

Dickson, A., Toft, A., \& O'Carroll, R. E. (2009). Neuropsychological functioning, illness perception, mood and quality of life in chronic fatigue syndrome, autoimmune thyroid disease and healthy participants. Psychological Medicine, 39(9), 1567-1576. $\quad$ http://dx.doi.org/10.1017 /s0033291708004960

Dierks, T., Jelic, V., Pascual-Marqui, R. D., Wahlund, L., Julin, P., Linden, D. E., ... Nordberg, A. (2000). Spatial pattern of cerebral glucose metabolism (PET) correlates with localization of intracerebral EEG-generators in Alzheimer's disease. Clinical Neurophysiology, 111(10), 1817-1824.

Dobbs, B. M., Dobbs, A. R., \& Kiss, I. (2001). Working memory deficits associated with chronic fatigue syndrome. Journal of the International Neuropsychological Society, 7(3), 285-293.

Duffy, F. H., McAnulty, G. B., McCreary, M. C., Cuchural, G. J., \& Komaroff, A. L. (2011). EEG spectral coherence data distinguish chronic fatigue syndrome patients from healthy controls and depressed patients: A case control study. BMC Neurology, 11, 82. http://dx.doi.org/10.1186/1471-2377-11-82

Elson, R. C., Huerta, R., Abarbanel, H. D. I., Rabinovich, M. I., \& Selverston, A. I. (1999). Dynamic control of irregular bursting in an identified neuron of an oscillatory circuit. Journal of Neurophysiology, 82(1), 115-122.

Fischer, D. B., William, A. H., Strauss, A. C., Unger, E. R., Jason, L. A., Marshall, G. D., Jr., \& Dimitrakoff, J. D. (2014). Chronic Fatigue Syndrome: The Current Status and Future Potentials of Emerging Biomarkers. Fatigue: Biomedicine, Health and Behavior, 2(2), 93-109. http://dx.doi.org/10.1080 /21641846.2014.906066

Fleminger, S., Oliver, D. L., Williams, W. H., \& Evans, J. (2003). The neuropsychiatry of depression after brain injury. Neuropsychological Rehabilitation, 13(1-2), 65-87. http://dx.doi.org/10.1080/09602010244000354

Flor-Henry, P., Lind, J. C., \& Koles, Z. J. (2010). EEG source analysis of chronic fatigue syndrome. Psychiatry Research, 181(2), 155-164. http://dx.doi.org/10.1016 /j.pscychresns.2009.10.007

Fox, M. D., Zhang, D., Snyder, A. Z., \& Raichle, M. E. (2009). The global signal and observed anticorrelated resting state brain networks. Journal of Neurophysiology, 101(6), 3270-3283. http://dx.doi.org/10.1152/jn.90777.2008

Frey, J. N., Ruhnau, P., \& Weisz, N. (2015). Not so different after all: The same oscillatory processes support different types of attention. Brain Research, 1626, 183-197. http://dx.doi.org /10.1016/j.brainres.2015.02.017

Friston, K. (2010). The free-energy principle: a unified brain theory? Nature Reviews Neuroscience, 11(2), 127-138. http://dx.doi.org/10.1038/nrn2787

Friston, K. J., Bastos, A. M., Pinotsis, D., \& Litvak, V. (2015). LFP and oscillations-what do they tell us? Current Opinion in Neurobiology, 31, 1-6. http://dx.doi.org/10.1016 /j.conb.2014.05.004

Fry, A. M., \& Martin, M. (1996). Fatigue in the chronic fatigue syndrome: a cognitive phenomenon? Journal of
Psychosomatic Research, 41(5), 415-426. http://dx.doi.org/10.1016/S0022-3999(96)00190-0

Fuster, J. M. (2009). The Prefrontal Cortex (4th ed.). Burlington, MA: Elsevier/Academic Press.

Gay, C. W., Robinson, M. E., Lai, S., O'Shea, A., Craggs, J. G., Price, D. D., \& Staud, R. (2016). Abnormal Resting-State Functional Connectivity in Patients with Chronic Fatigue Syndrome: Results of Seed and Data-Driven Analyses. Brain Connectivity, 6(1), 48-56. http://dx.doi.org/10.1089 /brain.2015.0366

Gianotti, L. R. R., Künig, G., Faber, P. L., Lehmann, D., PascualMarqui, R. D., Kochi, K., \& Schreiter-Gasser, U. (2008). Rivastigmine effects on EEG spectra and three-dimensional LORETA functional imaging in Alzheimer's disease. Psychopharmacology, 198(3), 323-332. http://dx.doi.org /10.1007/s00213-008-1111-1

Gianotti, L. R. R., Künig, G., Lehmann, D., Faber, P. L., PascualMarqui, R. D., Kochi, K., \& Schreiter-Gasser, U. (2007). Correlation between disease severity and brain electric LORETA tomography in Alzheimer's disease. Clinical Neurophysiology, 118(1), 186-196. http://dx.doi.org/10.1016 /j.clinph.2006.09.007

Gloor, P., Ball, G., \& Schaul, N. (1977). Brain lesions that produce delta waves in the EEG. Neurology, 27(4), 326-333. http://dx. doi.org/10.1212/WNL.27.4.326

Goedendorp, M. M., Bleijenberg, G., \& Knoop, H. (2014). Response to 'Underperformance of myalgic encephalomyelitis (ME)/chronic fatigue syndrome (CFS) patients at neurocognitive tests should be assessed objectively'. Journal of Psychosomatic Research, 76(4), 340. http://dx.doi.org /10.1016/j.jpsychores.2013.12.006

Grech, R., Cassar, T., Muscat, J., Camilleri, K. P., Fabri, S. G., Zervakis, M., ... Vanrumste, B. (2008). Review on solving the inverse problem in EEG source analysis. Journal of NeuroEngineering and Rehabilitation, 5, 25. http://dx.doi.org /10.1186/1743-0003-5-25

Greicius, M. D., Srivastava, G., Reiss, A. L., \& Menon, V. (2004). Default-mode network activity distinguishes Alzheimer's disease from healthy aging: evidence from functional MRI. Proceedings of the National Academy of Sciences of the United States of America, 101(13), 4637-4642. http://dx.doi.org/10.1073/pnas.0308627101

Griffith, J. P., \& Zarrouf, F. A. (2008). A systematic review of chronic fatigue syndrome: don't assume it's depression. Primary Care Companion to the Journal of Clinical Psychiatry, 10(2), 120-128.

Gu, S., Pasqualetti, F., Cieslak, M., Telesford, Q. K., Yu, A. B., Kahn, A. E., ... Bassett, D. S. (2015). Controllability of structural brain networks. Nature Communications, 6, 8414. http://dx.doi.org/10.1038/ncomms9414

Hagmann, P., Cammoun, L., Gigandet, X., Meuli, R., Honey, C. J., Wedeen, V. J., \& Sporns, O. (2008). Mapping the structural core of human cerebral cortex. PLoS Biology, 6(7), e159. http://dx.doi.org/10.1371/journal.pbio.0060159

Halassa, M. M., \& Haydon, P. G. (2010). Integrated brain circuits: astrocytic networks modulate neuronal activity and behavior. Annual Review of Physiology, 72, 335-355. http://dx.doi.org /10.1146/annurev-physiol-021909-135843

Haneef, Z., Lenartowicz, A., Yeh, H. J., Engel, J., Jr., \& Stern, J. M. (2014). Network analysis of the default mode network using functional connectivity MRI in Temporal Lobe Epilepsy. Journal of Visualized Experiments, (90), e51442. http://dx.doi.org/10.3791/51442

Havlicek, M., Roebroeck, A., Friston, K., Gardumi, A., Ivanov, D., \& Uludag, K. (2015). Physiologically informed dynamic causal modeling of fMRI data. Neurolmage, 122, 355-372. http://dx.doi.org/10.1016/j.neuroimage.2015.07.078

Hawk, C., Jason, L. A., \& Torres-Harding, S. (2006). Differential diagnosis of chronic fatigue syndrome and major depressive 
disorder. International Journal of Behavioral Medicine, 13(3), 244-251. http://dx.doi.org/10.1207/s15327558ijbm1303_8

Hellyer, P. J., Jachs, B., Clopath, C., \& Leech, R. (2015). Local inhibitory plasticity tunes macroscopic brain dynamics and allows the emergence of functional brain networks. Neurolmage, 124(Pt A), 85-95. http://dx.doi.org/10.1016 /j.neuroimage.2015.08.069

Heyder, K., Suchan, B., \& Daum, I. (2004). Cortico-subcortical contributions to executive control. Acta Psychologica, 115(23), 271-289. http://dx.doi.org/10.1016/j.actpsy.2003.12.010

Hillary, F. G., \& DeLuca, J. (Eds.). (2007). Functional Neuroimaging in Clinical Populations. New York, NY: Guilford Press.

Holmgren, M., \& Scheffer, M. (2010). Strong facilitation in mild environments: the stress gradient hypothesis revisited. Journal of Ecology, 98(6), 1269-1275. http://dx.doi.org /10.1111/j.1365-2745.2010.01709.x

Hou, J., Lin, Y., Zhang, W., Song, L., Wu, W., Wang, J., ... Li, H. (2013). Abnormalities of frontal-parietal resting-state functional connectivity are related to disease activity in patients with systemic lupus erythematosus. PloS ONE, 8(9), e74530. http://dx.doi.org/10.1371/journal.pone.0074530

Hughes, S. W., Lörincz, M., Cope, D. W., Blethyn, K. L., Kékesi, K. A., Parri, H. R., ... Crunelli, V. (2004). Synchronized oscillations at alpha and theta frequencies in the lateral geniculate nucleus. Neuron, 42(2), 253-268. http://dx.doi.org/ 10.1016/S0896-6273(04)00191-6

Ichise, M., Salit, I. E., Abbey, S. E., Chung, D.-G., Gray, B., Kirsh, J. C., \& Freedman, M. (1992). Assessment of regional cerebral perfusion by $99 \mathrm{Tcm}-\mathrm{HMPAO}$ SPECT in chronic fatigue syndrome. Nuclear Medicine Communications, 13(10), 767-772.

Jann, K., Hernandez, L. M., Beck-Pancer, D., McCarron, R. Smith, R. X., Dapretto, M., \& Wang, D. J. J. (2015). Altered resting perfusion and functional connectivity of default mode network in youth with autism spectrum disorder. Brain and Behavior, 5(9), e00358. http://dx.doi.org/10.1002/brb3.358

Jason, L. A., Zinn, M. L., \& Zinn, M. A. (2015). Myalgic Encephalomyelitis: Symptoms and Biomarkers. Current Neuropharmacology, 13(5), 701-734. http://dx.doi.org $/ 10.2174 / 1570159 \times 13666150928105725$

Johnson, E. L., \& Knight, R. T. (2015). Intracranial Recordings and Human Memory. Current Opinion in Neurobiology, 31, 18-25. http://dx.doi.org/10.1016/j.conb.2014.07.021

Jones, R., \& Bhattacharya, J. (2014). A role for the precuneus in thought-action fusion: evidence from participants with significant obsessive-compulsive symptoms. Neurolmage: Clinical, $\quad 4, \quad 112-121 . \quad$ http://dx.doi.org/10.1016 /j.nicl.2013.11.008

Kandel, E. R., Schwartz, J. H., Jessell, T. M., Siegelbaum, S. A., \& Hudspeth, A. J. (Eds.). (2012). Principles of Neural Science (5th ed.). New York, NY: McGraw Hill.

Kennedy, M. B., Beale, H. C., Carlisle, H. J., \& Washburn, L. R. (2005). Integration of biochemical signalling in spines. Nature Reviews Neuroscience, 6(6), 423-434. http://dx.doi.org /10.1038/nrn1685

Klimesch, W., Freunberger, R., Sauseng, P., \& Gruber, W. (2008). A short review of slow phase synchronization and memory: evidence for control processes in different memory systems? Brain Research, 1235, 31-44. http://dx.doi.org /10.1016/j.brainres.2008.06.049

Krupp, L. B., LaRocca, N. G., Muir-Nash, J., \& Steinberg, A. D. (1989). The fatigue severity scale. Application to patients with multiple sclerosis and systemic lupus erythematosus. Archives of Neurology, 46(10), 1121-1123. http://dx.doi.org /10.1001/archneur.1989.00520460115022

Krupp, L. B., Sliwinski, M., Masur, D. M., Friedberg, F., \& Coyle, P. K. (1994). Cognitive functioning and depression in patients with chronic fatigue syndrome and multiple sclerosis. Archives of Neurology, 51(7), 705-710.
Kuzis, G., Sabe, L., Tiberti, C., Dorrego, F., \& Starkstein, S. E. (1999). Neuropsychological correlates of apathy and depression in patients with dementia. Neurology, 52(7), 1403-1407.

LaManca, J. J., Sisto, S. A., DeLuca, J., Johnson, S. K., Lange, G., Pareja, J., ... Natelson, B. H. (1998). Influence of exhaustive treadmill exercise on cognitive functioning in chronic fatigue syndrome. The American Journal of Medicine, 105(3A), 59S-65S.

Lange, G., DeLuca, J., Maldjian, J. A., Lee, H., Tiersky, L. A., \& Natelson, B. H. (1999). Brain MRI abnormalities exist in a subset of patients with chronic fatigue syndrome. Journal of the Neurological Sciences, 171(1), 3-7.

Lange, G., Steffener, J., Cook, D. B., Bly, B. M., Christodoulou, C., Liu, W.-C., ... Natelson, B. H. (2005). Objective evidence of cognitive complaints in Chronic Fatigue Syndrome: a BOLD fMRI study of verbal working memory. Neurolmage, 26(2), $\quad 513-524 . \quad$ http://dx.doi.org/10.1016 /j.neuroimage.2005.02.011

Le Van Quyen, M., Martinerie, J., Navarro, V., Baulac, M., \& Varela, F. J. (2001). Characterizing neurodynamic changes before seizures. Journal of Clinical Neurophysiology, 18(3), 191-208.

Lewis, D. H., Mayberg, H. S., Fischer, M. E., Goldberg, J., Ashton, S., Graham, M. M., \& Buchwald, D. (2001). Monozygotic twins discordant for chronic fatigue syndrome: regional cerebral blood flow SPECT. Radiology, 219(3), 766773. http://dx.doi.org/10.1148/radiology.219.3.r01jn18766

Liu, Z., Ding, L., \& He, B. (2006). Integration of EEG/MEG with $\mathrm{MRI}$ and $\mathrm{fMRI}$. IEEE Engineering in Medicine and Biology Magazine, 25(4), 46-53.

Luria, A. R. (1980). Higher cortical functions in man (2nd ed.). New York: Basic Books Publishers.

MacHale, S. M., Lawŕie, S. M., Cavanagh, J. T., Glabus, M. F., Murray, C. L., Goodwin, G. M., \& Ebmeier, K. P. (2000). Cerebral perfusion in chronic fatigue syndrome and depression. The British Journal of Psychiatry, 176, 550-556.

Madhyastha, T. M., Askren, M. K., Boord, P., \& Grabowski, T. J. (2015). Dynamic connectivity at rest predicts attention task performance. Brain Connectivity, 5(1), 45-59. http://dx.doi.org /10.1089/brain.2014.0248

Maes, M. (2011). An intriguing and hitherto unexplained cooccurrence: Depression and chronic fatigue syndrome are manifestations of shared inflammatory, oxidative and nitrosative (IO\&NS) pathways. Progress in NeuroPsychopharmacology and Biological Psychiatry, 35(3), 784794. http://dx.doi.org/10.1016/j.pnpbp.2010.06.023

Majer, M., Welberg, L. A., Capuron, L., Miller, A. H., Pagnoni, G., \& Reeves, W. C. (2008). Neuropsychological performance in persons with chronic fatigue syndrome: results from a population-based study. Psychosomatic Medicine, 70(7), 829-836. http://dx.doi.org/10.1097/PSY.0b013e31817b9793

Mariman, A., Delesie, L., Tobback, E., Hanoulle, I., Sermijn, E., Vermeir, P., ... Vogelaers, D. (2013). Undiagnosed and comorbid disorders in patients with presumed chronic fatigue syndrome. Journal of Psychosomatic Research, 75(5), 491496. http://dx.doi.org/10.1016/j.jpsychores.2013.07.010

Marshall, P. S., Forstot, M., Callies, A., Peterson, P. K., \& Schenck, C. H. (1997). Cognitive slowing and working memory difficulties in chronic fatigue syndrome. Psychosomatic Medicine, 59(1), 58-66.

McCormick, D. A., \& Bal, T. (1997). Sleep and arousal: thalamocortical mechanisms. Annual Review of Neuroscience, 20, 185-215. http://dx.doi.org/10.1146 lannurev.neuro.20.1.185

McEwen, B. S. (2006). Protective and damaging effects of stress mediators: central role of the brain. Dialogues in Clinical Neuroscience, 8(4), 367-381.

McEwen, B. S., Bowles, N. P., Gray, J. D., Hill, M. N., Hunter, R. G., Karatsoreos, I. N., \& Nasca, C. (2015). Mechanisms of 
stress in the brain. Nature Neuroscience, 18(10), 1353-1363. http://dx.doi.org/10.1038/nn.4086

McPherson, S., Fairbanks, L., Tiken, S., Cummings, J. L., \& BackMadruga, C. (2002). Apathy and executive function in Alzheimer's disease. Journal of the International Neuropsychological Society, 8(3), 373-381.

Menon, V. (2011). Large-scale brain networks and psychopathology: a unifying triple network model. Trends in Cognitive Sciences, 15(10), 483-506. http://dx.doi.org /10.1016/j.tics.2011.08.003

Menon, V. (2012). Functional connectivity, neurocognitive networks, and brain dynamics. In M. I. Rabinovich, K. J. Friston \& P. Varona (Eds.), Principles of Brain Dynamics: Global State Interactions (pp. 27-47). Cambridge, MA: The MIT Press.

Metherate, R., \& Ashe, J. H. (1993). Ionic flux contributions to neocortical slow waves and nucleus basalis-mediated activation: whole-cell recordings in vivo. The Journal of Neuroscience, 13(12), 5312-5323.

Metzger, F. A., \& Denney, D. R. (2002). Perception of cognitive performance in patients with chronic fatigue syndrome. Annals Of Behavioral Medicine, 24(2), 106-112.

Michel, C. M., \& Murray, M. M. (2012). Towards the utilization of EEG as a brain imaging tool. Neurolmage, 61(2), 371-385. http://dx.doi.org/10.1016/j.neuroimage.2011.12.039

Michiels, V., \& Cluydts, R. (2001). Neuropsychological functioning in chronic fatigue syndrome: a review. Acta Psychiatrica Scandinavica, 103(2), 84-93. http://dx.doi.org/10.1034/j.16000447.2001.00017.x

Moazami-Goudarzi, M., Sarnthein, J., Michels, L., Moukhtieva, R., \& Jeanmonod, D. (2008). Enhanced frontal low and high frequency power and synchronization in the resting EEG of parkinsonian patients. Neurolmage, 41(3), 985-997. http://dx.doi.org/10.1016/j.neuroimage.2008.03.032

Morris, G., \& Maes, M. (2012). A neuro-immune model of Myalgic Encephalomyelitis/Chronic fatigue syndrome. Metabolic Brain Disease, 28(4), 523-540. http://dx.doi.org/10.1007/s11011012-9324-8

Mulert, C., Jäger, L., Schmitt, R., Bussfeld, P., Pogarell, O., Möller, H.-J., ... Hegerl, U. (2004). Integration of fMRI and simultaneous EEG: towards a comprehensive understanding of localization and time-course of brain activity in target detection. Neurolmage, 22(1), 83-94. http://dx.doi.org /10.1016/j.neuroimage.2003.10.051

Musso, F., Brinkmeyer, J., Mobascher, A., Warbrick, T., \& Winterer, G. (2010). Spontaneous brain activity and EEG microstates. A novel EEG/fMRI analysis approach to explore resting-state networks. Neurolmage, 52(4), 1149-1161. http://dx.doi.org/10.1016/j.neuroimage.2010.01.093

Nakatomi, Y., Mizuno, K., Ishii, A., Wada, Y., Tanaka, M., Tazawa, S., ... Watanabe, Y. (2014). Neuroinflammation in patients with Chronic Fatigue Syndrome/Myalgic Encephalomyelitis: An ${ }^{11} \mathrm{C}-(\mathrm{R})-\mathrm{PK} 11195$ PET study. Journal of Nuclear Medicine, 55(6), 945-950. http://dx.doi.org /10.2967/jnumed.113.131045

Natelson, B. H., Cohen, J. M., Brassloff, I., \& Lee, H. J. (1993). A controlled study of brain magnetic resonance imaging in patients with the chronic fatigue syndrome. Journal of the Neurological Sciences, 120(2), 213-217.

Neu, D., Kajosch, H., Peigneux, P., Verbanck, P., Linkowski, P., \& Le Bon, O. (2011). Cognitive impairment in fatigue and sleepiness associated conditions. Psychiatry Research, 189(1), 128-134. http://dx.doi.org/10.1016 lj.psychres.2010.12.005

Niedermeyer, E., \& Lopes da Silva, F. H. (2005). Electroencephalography: Basic principles, clinical applications and related fields (5th ed.). Philadelphia, PA: Lippincott Williams and Wilkins.

Nijs, J., Van Oosterwijck, J., Meeus, M., Lambrecht, L., Metzger, K., Frémont, M., \& Paul, L. (2010). Unravelling the nature of postexertional malaise in myalgic encephalomyelitis/chronic fatigue syndrome: the role of elastase, complement $\mathrm{C} 4 \mathrm{a}$ and interleukin-1beta. Journal of Internal Medicine, 267(4), 418435. http://dx.doi.org/10.1111/j.1365-2796.2009.02178.x

Nishida, K., Yoshimura, M., Isotani, T., Yoshida, T., Kitaura, Y., Saito, A., ... Kinoshita, T. (2011). Differences in quantitative EEG between frontotemporal dementia and Alzheimer's disease as revealed by LORETA. Clinical Neurophysiology, 122(9), 1718-1725. http://dx.doi.org/10.1016 /j.clinph.2011.02.011

Nolte, G., \& Müller, K.-R. (2010). Localizing and estimating causal relations of interacting brain rhythms. Frontiers in Human Neuroscience, 4, 209. http://dx.doi.org/10.3389 /fnhum.2010.00209

Nolte, G., Ziehe, A., Nikulin, V. V., Schlögl, A., Krämer, N., Brismar, T., \& Müller, K.-R. (2008). Robustly estimating the flow direction of information in complex physical systems. Physical Review Letters, 100(23), 234101.

Nolte, J. (2009). The Human Brain: An Introduction to its Functional Anatomy (6th ed.). Philadelphia, PA: Mosby/Elsevier.

Nunez, P. L., Srinivasan, R., \& Fields, R. D. (2014). EEG functional connectivity, axon delays and white matter disease. Clinical Neurophysiology, 126(1), 110-120. http://dx.doi.org /10.1016/j.clinph.2014.04.003

Ocon, A. J. (2013). Caught in the thickness of brain fog: exploring the cognitive symptoms of Chronic Fatigue Syndrome. Frontiers in Physiology, 4, 63. http://dx.doi.org/10.3389 /fphys.2013.00063

Okada, T., Tanaka, M., Kuratsune, H., Watanabe, Y., \& Sadato, N. (2004). Mechanisms underlying fatigue: a voxel-based morphometric study of chronic fatigue syndrome. BMC Neurology, 4(1), 14. http://dx.doi.org/10.1186/1471-2377-4-14

Olbrich, S., Olbrich, H., Jahn, I., Sander, C., Adamaszek, M., Hegerl, U., ... Stengler, K. (2013). EEG-vigilance regulation during the resting state in obsessive-compulsive disorder. Clinical Neurophysiology, 124(3), 497-502. http://dx.doi.org /10.1016/j.clinph.2012.08.018

Olbrich, S., Tränkner, A., Chittka, T., Hegerl, U., \& Schönknecht, P. (2014). Functional connectivity in major depression: increased phase synchronization between frontal cortical EEG-source estimates. Psychiatry Research, 222(1-2), 9199. http://dx.doi.org/10.1016/j.pscychresns.2014.02.010

Olvet, D. M., Delaparte, L., Yeh, F.-C., DeLorenzo, C., McGrath, P. J., Weissman, M. M., ... Parsey, R. V. (2015). A comprehensive examination of white matter tracts and connectometry in major depressive disorder. Depression and Anxiety, 33(1), 56-65. http://dx.doi.org/10.1002/da.22445

Pachner, A. R. (2012). A Primer of Neuroimmunological Disease. New York: Springer.

Papageorgiou, C. C., Sfagos, C., Kosma, K. K., Kontoangelos, K. A., Triantafyllou, N., Vassilopoulos, D., ... Soldatos, C. R. (2007). Changes in LORETA and conventional patterns of P600 after steroid treatment in multiple sclerosis patients. Progress in Neuro-Psychopharmacology and Biological Psychiatry, 31(1), 234-241. http://dx.doi.org/10.1016 /j.pnpbp.2006.07.005

Pascual-Marqui, R. D., Biscay, R. J., Bosch-Bayard, J., Lehmann, D., Kochi, K., Kinoshita, T., ... Sadato, N. (2014). Assessing direct paths of intracortical causal information flow of oscillatory activity with the isolated effective coherence (iCoh). Frontiers in Human Neuroscience, 8. http://dx.doi.org /10.3389/fnhum.2014.00448

Pascual-Marqui, R. D., Esslen, M., Kochi, K., \& Lehmann, D. (2002). Functional imaging with low-resolution brain electromagnetic tomography (LORETA): a review. Methods and Findings in Experimental and Clinical Pharmacology, 24(Suppl. C), 91-95.

Pascual-Marqui, R. D., Lehmann, D., Koukkou, M., Kochi, K., Anderer, P., Saletu, B., ... Kinoshita, T. (2011). Assessing 
interactions in the brain with exact low-resolution electromagnetic tomography. Philosophical Transactions of the Royal Society A, 369(1952), 3768-3784. http://dx.doi.org /10.1098/rsta.2011.0081

Pascual-Marqui, R. D., Michel, C. M., \& Lehmann, D. (1994). Low resolution electromagnetic tomography: a new method for localizing electrical activity in the brain. International Journal of Psychophysiology, 18(1), 49-65.

Pazderka-Robinson, H., Morrison, J. W., \& Flor-Henry, P. (2004). Electrodermal dissociation of chronic fatigue and depression: evidence for distinct physiological mechanisms. International Journal of Psychophysiology, 53(3), 171-182. http://dx.doi.org/10.1016/j.ijpsycho.2004.03.004

Pellerin, L., \& Magistretti, P. J. (1994). Glutamate uptake into astrocytes stimulates aerobic glycolysis: a mechanism coupling neuronal activity to glucose utilization. Proceedings of the National Academy of Sciences of the United States of America, 91(22), 10625-10629.

Perrin, R., Embleton, K., Pentreath, V. W., \& Jackson, A. (2010). Longitudinal MRI shows no cerebral abnormality in chronic fatigue syndrome. The British Journal of Radiology, 83(989), 419-423. http://dx.doi.org/10.1259/bjr/85621779

Pinal, D., Zurrón, M., Díaz, F., \& Sauseng, P. (2015). Stuck in default mode: inefficient cross-frequency synchronization may lead to age-related short-term memory decline. Neurobiology of Aging, 36(4), 1611-1618. http://dx.doi.org/10.1016 /j.neurobiolaging.2015.01.009

Pizzagalli, D. A., Oakes, T. R., Fox, A. S., Chung, M. K., Larson, C. L., Abercrombie, H. C., ... Davidson, R. J. (2004). Functional but not structural subgenual prefrontal cortex abnormalities in melancholia. Molecular Psychiatry, 9(4), 393-405. http://dx.doi.org/10.1038/sj.mp.4001469

Poldrack, R. A., Mumford, J. A., \& Nichols, T. E. (2011). Handbook of Functional MRI Data Analysis. New York: Cambridge University Press.

Prasher, D., Smith, A., \& Findley, L. (1990). Sensory and cognitive event-related potentials in myalgic encephalomyelitis. Journal of Neurology, Neurosurgery, and Psychiatry, 53(3), 247-253.

Purger, D., Gibson, E. M., \& Monje, M. (2015). Myelin plasticity in the central nervous system. Neuropharmacology. Advance online publication. $\quad \mathrm{http} / / / \mathrm{dx}$.doi.org/10.1016 /j.neuropharm.2015.08.001

Puri, B. K., Jakeman, P. M., Agour, M., Gunatilake, K. D. R., Fernando, K. A. C., Gurusinghe, A. I., ... Gishen, P. (2012). Regional grey and white matter volumetric changes in myalgic encephalomyelitis (chronic fatigue syndrome): a voxel-based morphometry 3 T MRI study. The British Journal of Radiology, 85(1015), e270-273. http://dx.doi.org/ $10.1259 / \mathrm{bjr} / 93889091$

Rabinovich, M. I., Afraimovich, V. S., Bick, C., \& Varona, P. (2012). Information flow dynamics in the brain. Physics of Life Reviews, 9(1), 51-73. http://dx.doi.org/10.1016 /j.plrev.2011.11.002

Rabinovich, M. I., Friston, K. J., \& Varona, P. (Eds.). (2012). Principles of Brain Dynamics: Global State Interactions. Cambridge, MA: The MIT Press.

Raichle, M. E. (2010). Two views of brain function. Trends in Cognitive Sciences, 14(4), 180-190. http://dx.doi.org/10.1016 /j.tics.2010.01.008

Raichle, M. E. (2011). The restless brain. Brain Connectivity, 1(1), 3-12. http://dx.doi.org/10.1089/brain.2011.0019

Raichle, M. E., MacLeod, A. M., Snyder, A. Z., Powers, W. J., Gusnard, D. A., \& Shulman, G. L. (2001). A default mode of brain function. Proceedings of the National Academy of Sciences of the United States of America, 98(2), 676-682. http://dx.doi.org/10.1073/pnas.98.2.676

Romei, V., Gross, J., \& Thut, G. (2012). Sounds reset rhythms of visual cortex and corresponding human visual perception.
Current Biology, 22(9), 807-813. http://dx.doi.org/10.1016 /j.cub.2012.03.025

Ropper, A. H., \& Samuels, M. A. (2009). Adams \& Victor's Principles of Neurology (9th ed.). New York, NY: McGraw-Hill.

Sandman, C. A., Barron, J. L., Nackoul, K., Goldstein, J., \& Fidler, F. (1993). Memory deficits associated with chronic fatigue immune dysfunction syndrome. Biological Psychiatry, 33(89), 618-623.

Santamarina-Perez, P., Eiroa-Orosa, F. J., Freniche, V., MorenoMayos, A., Alegre, J., Saez, N., \& Jacas, C. (2011). Length of illness does not predict cognitive dysfunction in chronic fatigue syndrome. Applied Neuropsychology, 18(3), 216-222. http://dx.doi.org/10.1080/09084282.2011.595448

Saper, C. B., Fuller, P. M., Pedersen, N. P., Lu, J., \& Scammell, T. E. (2010). Sleep state switching. Neuron, 68(6), 10231042. http://dx.doi.org/10.1016/j.neuron.2010.11.032

Schaul, N., Lueders, H., \& Sachdev, K. (1981). Generalized, bilaterally synchronous bursts of slow waves in the EEG. Archives of Neurology, 38(11), 690-692.

Schmaling, K. B., Lewis, D. H., Fiedelak, J. I., Mahurin, R., \& Buchwald, D. S. (2003). Single-photon emission computerized tomography and neurocognitive function in patients with chronic fatigue syndrome. Psychosomatic Medicine, 65(1), 129-136.

Schwartz, R. B., Garada, B. M., Komaroff, A. L., Tice, H. M., Gleit, M., Jolesz, F. A., \& Holman, B. L. (1994). Detection of intracranial abnormalities in patients with chronic fatigue syndrome: comparison of MR imaging and SPECT. American Journal of Roentgenology, 162(4), 935-941. http://dx.doi.org/10.2214/ajr.162.4.8141020

Schwartz, R. B., Komaroff, A. L., Garada, B. M., Gleit, M., Doolittle, T. H., Bates, D. W., ... Holman, B. L. (1994). SPECT imaging of the brain: comparison of findings in patients with chronic fatigue syndrome, AIDS dementia complex, and major unipolar depression. American Journal of Roentgenology, 162(4), 943-951. http://dx.doi.org/10.2214 lajr.162.4.8141022

Sherlin, L., Budzynski, T., Kogan Budzynski, H., Congedo, M., Fischer, M. E., \& Buchwald, D. (2007). Low-resolution electromagnetic brain tomography (LORETA) of monozygotic twins discordant for chronic fatigue syndrome. Neurolmage, 34(4), $\quad$ 1438-1442. http://dx.doi.org/10.1016 /j.neuroimage.2006.11.007

Sherman, S. M., \& Guillery, R. W. (1996). Functional organization of thalamocortical relays. Journal of Neurophysiology, 76(3), $1367-1395$.

Short, K., McCabe, M., \& Tooley, G. (2002). Cognitive functioning in chronic fatigue syndrome and the role of depression, anxiety, and fatigue. Journal of Psychosomatic Research, 52(6), 475-483. http://dx.doi.org/10.1016/S00223999(02)00290-8

Shulman, R. G., Rothman, D. L., Behar, K. L., \& Hyder, F. (2004). Energetic basis of brain activity: implications for neuroimaging. Trends in Neurosciences, 27(8), 489-495. http://dx.doi.org/10.1016/j.tins.2004.06.005

Siemionow, V., Fang, Y., Calabrese, L., Sahgal, V., \& Yue, G. H. (2004). Altered central nervous system signal during motor performance in chronic fatigue syndrome. Clinical Neurophysiology, 115(10), 2372-2381. http://dx.doi.org /10.1016/j.clinph.2004.05.012

Siessmeier, T., Nix, W. A., Hardt, J., Schreckenberger, M., Egle, U. T., \& Bartenstein, P. (2003). Observer independent analysis of cerebral glucose metabolism in patients with chronic fatigue syndrome. Journal of Neurology, Neurosurgery, and Psychiatry, 74(7), 922-928. http://dx.doi.org/10.1136/jnnp.74.7.922

Smets, E. M. A., Garssen, B., Bonke, B., \& De Haes, J. C. J. M. (1995). The Multidimensional Fatigue Inventory (MFI) psychometric qualities of an instrument to assess fatigue. 
Journal of Psychosomatic Research, 39(3), 315-325. http://dx.doi.org/10.1016/0022-3999(94)00125-O

Smith, A. P., Behan, P. O., Bell, W., Millar, K., \& Bakheit, M. (1993). Behavioural problems associated with the chronic fatigue syndrome. British Journal Of Psychology, 84(Pt 3), 411-423.

Sponheim, S. R., McGuire, K. A., Kang, S. S., Davenport, N. D., Aviyente, S., Bernat, E. M., \& Lim, K. O. (2011). Evidence of disrupted functional connectivity in the brain after combatrelated blast injury. Neurolmage, 54(Suppl. 1), S21-S29. http://dx.doi.org/10.1016/j.neuroimage.2010.09.007

Sporns, O. (2013). Structure and function of complex brain networks. Dialogues in Clinical Neuroscience, 15(3), 247262.

Stam, C. J. (2014). Modern network science of neurological disorders. Nature Reviews Neuroscience, 15(10), 683-695. http://dx.doi.org/10.1038/nrn3801

Stam, C. J., van Cappellen van Walsum, A. M., Pijnenburg, Y. A., Berendse, H. W., de Munck, J. C., Scheltens, P., \& van Dijk, B. W. (2002). Generalized synchronization of MEG recordings in Alzheimer's Disease: evidence for involvement of the gamma band. Journal of Clinical Neurophysiology, 19(6), 562-574. http://dx.doi.org/10.1097/00004691-20021200000010

Stanton, B. R., \& Carson, A. (2016). Apathy: A practical guide for neurologists. Practical Neurology, 16(1), 42-47. http://dx.doi.org/10.1136/practneurol-2015-001232

Stefanics, G., Hangya, B., Hernádi, I., Winkler, I., Lakatos, P., \& Ulbert, I. (2010). Phase entrainment of human delta oscillations can mediate the effects of expectation on reaction speed. The Journal of Neuroscience, 30(41), 13578-13585. http://dx.doi.org/10.1523/jneurosci.0703-10.2010

Steriade, M. (2006). Grouping of brain rhythms in corticothalamic systems. Neuroscience, 137(4), 1087-1106. http://dx.doi.org/10.1016/j.neuroscience.2005.10.029

Steriade, M., \& Paré, D. (2006). Gating in cerebral networks. New York, NY: Cambridge University Press.

Stranahan, A. M., \& Mattson, M. P. (2008). Impact of energy intake and expenditure on neuronal plasticity. NeuroMolecular Medicine, 10(4), 209-218. http://dx.doi.org/10.1007/s12017008-8043-0

Stratton, P., \& Wiles, J. (2015). Global segregation of cortical activity and metastable dynamics. Frontiers in Systems Neuroscience, $\quad 9, \quad 119 . \quad$ http://dx.doi.org/10.3389 /fnsys.2015.00119

Strauss, E., Sherman, E. M. S., \& Spreen, O. (2006). A Compendium of Neuropsychological Tests: Administration, Norms, and Commentary (3rd ed.). New York, NY: Oxford University Press.

Styliadis, C., Kartsidis, P., Paraskevopoulos, E., loannides, A. A., \& Bamidis, P. D. (2015). Neuroplastic effects of combined computerized physical and cognitive training in elderly individuals at risk for dementia: an eLORETA controlled study on resting states. Neural Plasticity, 2015, 172192. http://dx.doi.org/10.1155/2015/172192

Tanaka, M., Sadato, N., Okada, T., Mizuno, K., Sasabe, T., Tanabe, H. C., ... Watanabe, Y. (2006). Reduced responsiveness is an essential feature of chronic fatigue syndrome: a fMRI study. BMC Neurology, 6, 9 http://dx.doi.org/10.1186/1471-2377-6-9

Tang, Y.-Y., Rothbart, M. K., \& Posner, M. I. (2012). Neural correlates of establishing, maintaining, and switching brain states. Trends in Cognitive Sciences, 16(6), 330-337. http://dx.doi.org/10.1016/j.tics.2012.05.001

Thatcher, R. W. (2011). Neuropsychiatry and Quantitative EEG in the 21st Century. Neuropsychiatry, 1(5), 495-514. http://dx.doi.org/10.2217/npy.11.45

Thatcher, R. W. (2012). Handbook of Quantitative Electroencephalography and EEG Biofeedback. St Petersburg, FL: ANI Publishing.
Thatcher, R. W. (2015). Handbook of Quantitative Electroencephalography and EEG Biofeedback. St. Petersburg, FL: ANI Publishing.

Thatcher, R. W., \& John, E. R. (1977). Foundations of Cognitive Processes (Vol. 1). Hillsdale, NJ: Lawrence Erlbaum.

Thatcher, R. W., North, D., \& Biver, C. (2005). EEG and intelligence: relations between EEG coherence, EEG phase delay and power. Clinical Neurophysiology, 116(9), 21292141. http://dx.doi.org/10.1016/j.clinph.2005.04.026

Thatcher, R. W., North, D. M., \& Biver, C. J. (2008). Intelligence and EEG phase reset: a two compartmental model of phase shift and lock. Neurolmage, 42(4), 1639-1653. http://dx.doi.org/10.1016/j.neuroimage.2008.06.009

Thatcher, R. W., North, D. M., \& Biver, C. J. (2012). Diffusion spectral imaging modules correlate with EEG LORETA neuroimaging modules. Human Brain Mapping, 33(5), 10621075. http:/dx.doi.org/10.1002/hbm. 21271

Thatcher, R. W., North, D. M., \& Biver, C. J. (2014). LORETA EEG phase reset of the default mode network. Frontiers in Human Neuroscience, 8, 529. http://dx.doi.org/10.3389 /fnhum.2014.00529

Thatcher, R. W., North, D. M., Curtin, R. T., Walker, R. A., Biver, C. J., Gomez, J. F., \& Salazar, A. M. (2001). An EEG severity index of traumatic brain injury. Journal of Neuropsychiatry and Clinical Neurosciences, 13(1), 77-87.

Thatcher, R. W., North, D. M., Neubrander, J., Biver, C. J., Cutler, S., \& DeFina, P. (2009). Autism and EEG phase reset: deficient GABA mediated inhibition in thalamo-cortical circuits. Developmental Neuropsychology, 34(6), 780-800. http://dx.doi.org/10.1080/87565640903265178

Thomas, M., \& Smith, A. (2009). An investigation into the cognitive deficits associated with chronic fatigue syndrome. The Open Neurology Journal, 3, 13-23. http://dx.doi.org/10.2174/1874205x00903010013

Tiersky, L. A., DeLuca, J., Hill, N., Dhar, S. K., Johnson, S. K., Lange, G., ... Natelson, B. H. (2001). Longitudinal assessment of neuropsychological functioning, psychiatric status, functional disability and employment status in chronic fatigue syndrome. Applied Neuropsychology, 8(1), 41-50. http://dx.doi.org/10.1207/s15324826an0801_6

Tiersky, L. A., Johnson, S. K., Lange, G., Natelson, B. H., \& DeLuca, J. (1997). Neuropsychology of chronic fatigue syndrome: a critical review. Journal of Clinical and Experimental Neuropsychology, 19(4), 560-586. http://dx.doi.org/10.1080/01688639708403744

Tirelli, U., Chierichetti, F., Tavio, M., Simonelli, C., Bianchin, G., Zanco, P., \& Ferlin, G. (1998). Brain positron emission tomography (PET) in chronic fatigue syndrome: preliminary data. The American Journal of Medicine, 105(3A), 54S-58S.

Todder, D., Levine, J., Abujumah, A., Mater, M., Cohen, H., \& Kaplan, Z. (2012). The quantitative electroencephalogram and the low-resolution electrical tomographic analysis in posttraumatic stress disorder. Clinical EEG and Neuroscience, 43(1), 48-53.

Toth, M., Faludi, B., Wackermann, J., Czopf, J., \& Kondakor, I. (2009). Characteristic changes in brain electrical activity due to chronic hypoxia in patients with obstructive sleep apnea syndrome (OSAS): a combined EEG study using LORETA and omega complexity. Brain Topography, 22(3), 185-190. http://dx.doi.org/10.1007/s10548-009-0110-9

Tristan, I., Rulkov, N. F., Huerta, R., \& Rabinovich, M. (2014). Timing control by redundant inhibitory neuronal circuits. Chaos, 24(1), 013124. http://dx.doi.org/10.1063/1.4866580

Twisk, F. N. M. (2014). Underperformance of myalgic encephalomyelitis (ME)/chronic fatigue syndrome (CFS) patients at neurocognitive tests should be assessed objectively without an a priori judgment about the etiology. Journal of Psychosomatic Research, 76(4), 339. http://dx.doi.org/10.1016/j.jpsychores.2013.10.016 
Van Den Eede, F., Moorkens, G., Hulstijn, W., Maas, Y., Schrijvers, D., Stevens, S. R., ... Sabbe, B. G. C. (2011). Psychomotor function and response inhibition in chronic fatigue syndrome. Psychiatry Research, 186(2-3), 367-372. http://dx.doi.org/10.1016/j.psychres.2010.07.022

van den Heuvel, M. P., \& Sporns, O. (2013). Network hubs in the human brain. Trends in Cognitive Sciences, 17(12), 683-696. http://dx.doi.org/10.1016/j.tics.2013.09.012

van Eimeren, T., Monchi, O., Ballanger, B., \& Strafella, A. P. (2009). Dysfunction of the default mode network in Parkinson disease: a functional magnetic resonance imaging study. Archives of Neurology, 66(7), 877-883. http://dx.doi.org /10.1001/archneurol.2009.97

van Straaten, E. C. W., \& Stam, C. J. (2013). Structure out of chaos: functional brain network analysis with EEG, MEG, and functional MRI. European Neuropsychopharmacology, 23(1), 7-18. http://dx.doi.org/10.1016/j.euroneuro.2012.10.010

Vancampfort, D., Stubbs, B., Venigalla, S. K., \& Probst, M. (2015). Adopting and maintaining physical activity behaviours in people with severe mental illness: The importance of autonomous motivation. Preventive Medicine, 81, 216-220. http://dx.doi.org/10.1016/j.ypmed.2015.09.006

Vanneste, S., Plazier, M., van der Loo, E., Van de Heyning, P., Congedo, M., \& De Ridder, D. (2010). The neural correlates of tinnitus-related distress. Neurolmage, 52(2), 470-480. http://dx.doi.org/10.1016/j.neuroimage.2010.04.029

Varela, C. (2014). Thalamic neuromodulation and its implications for executive networks. Frontiers in Neural Circuits, 8, 69. http://dx.doi.org/10.3389/fncir.2014.00069

Vecchio, F., Miraglia, F., Valeriani, L., Scarpellini, M. G., Bramanti, P., Mecarelli, O., \& Rossini, P. M. (2015). Cortical Brain Connectivity and B-Type Natriuretic Peptide in Patients With Congestive Heart Failure. Clinical EEG and Neuroscience, 46(3), 224-229. http://dx.doi.org/10.1177 $/ 1550059414529765$

Velikova, S., Locatelli, M., Insacco, C., Smeraldi, E., Comi, G., \& Leocani, L. (2010). Dysfunctional brain circuitry in obsessivecompulsive disorder: source and coherence analysis of EEG rhythms. Neurolmage, 49(1), 977-983. http://dx.doi.org /10.1016/j.neuroimage.2009.08.015

Velikova, S., Magnani, G., Arcari, C., Falautano, M., Franceschi, M., Comi, G., \& Leocani, L. (2011). Cognitive impairment and EEG background activity in adults with Down's syndrome: a topographic study. Human Brain Mapping, 32(5), 716-729. http://dx.doi.org/10.1002/hbm.21061

Vitacco, D., Brandeis, D., Pascual-Marqui, R., \& Martin, E. (2002). Correspondence of event-related potential tomography and functional magnetic resonance imaging during language processing. Human Brain Mapping, 17(1), 4-12. http://dx.doi.org/10.1002/hbm.10038

Volpe, U., Mucci, A., Bucci, P., Merlotti, E., Galderisi, S., \& Maj, M. (2007). The cortical generators of P3a and P3b: a LORETA study. Brain Research Bulletin, 73(4-6), 220-230. http://dx.doi.org/10.1016/j.brainresbull.2007.03.003

Wacker, J., Dillon, D. G., \& Pizzagalli, D. A. (2009). The role of the nucleus accumbens and rostral anterior cingulate cortex in anhedonia: integration of resting EEG, fMRI, and volumetric techniques. Neurolmage, 46(1), 327-337. http://dx.doi.org/10.1016/j.neuroimage.2009.01.058

Warren, J. W., Langenberg, P., \& Clauw, D. J. (2013). The number of existing functional somatic syndromes (FSSs) is an important risk factor for new, different FSSs. Journal Of Psychosomatic Research, 74(1), 12-17. http://dx.doi.org/10.1016/j.jpsychores.2012.09.002

Wearden, A., \& Appleby, L. (1997). Cognitive performance and complaints of cognitive impairment in chronic fatigue syndrome (CFS). Psychological Medicine, 27(1), 81-90.

Westmoreland, B. (2005). The EEG in Cerebral Inflammatory Processes. In E. Niedermeyer \& F. H. Lopes da Silva (Eds.) Electroencephalography: Basic principles, clinical applications and related fields (5th ed., pp. 323-337). Philadelphia, PA: Lippincott Williams and Wilkins.

White, P. D. (2010). Chronic fatigue syndrome: Is it one discrete syndrome or many? Implications for the "one vs. many" functional somatic syndromes debate. Journal of Psychosomatic Research, 68(5), 455-459. http://dx.doi.org /10.1016/j.jpsychores.2010.01.008

Worrell, G. A., Lagerlund, T. D., Sharbrough, F. W., Brinkmann, B. H., Busacker, N. E., Cicora, K. M., \& O'Brien, T. J. (2000). Localization of the epileptic focus by low-resolution electromagnetic tomography in patients with a lesion demonstrated by MRI. Brain Topography, 12(4), 273-282.

Wright, K. P., Lowry, C. A., \& LeBourgeois, M. K. (2012). Circadian and wakefulness-sleep modulation of cognition in humans. Frontiers in Molecular Neuroscience, 5, 50. http://dx.doi.org/10.3389/fnmol.2012.00050

Wulff, K., Gatti, S., Wettstein, J. G., \& Foster, R. G. (2010). Sleep and circadian rhythm disruption in psychiatric and neurodegenerative disease. Nature Reviews Neuroscience, 11(8), 589-599. http://dx.doi.org/10.1038/nrn2868

Xu, Y., Xu, G., Wu, G., Antuono, P., Rowe, D. B., \& Li, S.-J. (2008). The phase shift index for marking functional asynchrony in Alzheimer's disease patients using fMRI. Magnetic Resonance Imaging, 26(3), 379-392. http://dx.doi.org/10.1016/j.mri.2007.07.007

Yamamoto, S., Ouchi, Y., Nakatsuka, D., Tahara, T., Mizuno, K., Tajima, S., ... Watanabe, Y. (2012). Reduction of $\left[{ }^{11} \mathrm{C}\right](+) 3-$ MPB binding in brain of chronic fatigue syndrome with serum autoantibody against muscarinic cholinergic receptor. PloS ONE, 7(12), e51515. http://dx.doi.org/10.1371 /journal.pone.0051515

Yancey, J. R., \& Thomas, S. M. (2012). Chronic fatigue syndrome: diagnosis and treatment. American Family Physician, 86(8), 741-746.

Yao, B., Bagnato, F., Matsuura, E., Merkle, H., van Gelderen, P., Cantor, F. K., \& Duyn, J. H. (2012). Chronic multiple sclerosis lesions: characterization with high-field-strength MR imaging. Radiology, 262(1), 206-215. http://dx.doi.org/10.1148 /radiol.11110601

York, G. K., \& Steinberg, D. A. (2011). Hughlings Jackson's neurological ideas. Brain, 134(10), 3106-3113. http://dx.doi.org/10.1093/brain/awr219

Zhan, X. J., Cox, C. L., Rinzel, J., \& Sherman, S. M. (1999). Current clamp and modeling studies of low-threshold calcium spikes in cells of the cat's lateral geniculate nucleus. Journal of Neurophysiology, 81(5), 2360-2373.

Zhang, B., Lin, P., Shi, H., Öngür, D., Auerbach, R. P., Wang, X., ... Wang, X. (2015). Mapping anhedonia-specific dysfunction in a transdiagnostic approach: an ALE metaanalysis. Brain Imaging and Behavior. Advance online publication. http://dx.doi.org/10.1007/s11682-015-9457-6

Zhou, F., Zhuang, Y., Gong, H., Wang, B., Wang, X., Chen, Q., ... Wan, H. (2014). Altered inter-subregion connectivity of the default mode network in relapsing remitting multiple sclerosis: a functional and structural connectivity study. PloS ONE, 9(7), e101198. http://dx.doi.org/10.1371/journal.pone.0101198

Zinn, M. A., Zinn, M. L., Norris, J. L., Valencia, I., Montoya, J. G., \& Maldonado, J. R. (2014, March). Cortical hypoactivation during resting EEG suggests central nervous system pathology in patients with Chronic Fatigue Syndrome. Paper presented at the Symposium conducted at the meeting of IACFS/ME 2014 Biennial Conference, San Francisco, CA, USA.

Zinn, M. L., Zinn, M. A., Norris, J. L., Valencia, I., Montoya, J. G., \& Maldonado, J. R. (2014, March). EEG Peak Alpha Frequency Correlates in Chronic Fatigue Syndrome: A CaseControl Observational Study. Paper presented at the IACFS/ME 2014 Biennial Conference, San Francisco, CA, USA. 
Zumsteg, D., Friedman, A., Wieser, H. G., \& Wennberg, R. A. (2006). Propagation of interictal discharges in temporal lobe epilepsy: correlation of spatiotemporal mapping with intracranial foramen ovale electrode recordings. Clinical Neurophysiology, 117(12), 2615-2626. http://dx.doi.org /10.1016/j.clinph.2006.07.319

Zumsteg, D., Lozano, A. M., Wieser, H. G., \& Wennberg, R. A. (2006). Cortical activation with deep brain stimulation of the anterior thalamus for epilepsy. Clinical Neurophysiology, 117(1), 192-207. http://dx.doi.org/10.1016 /j.clinph.2005.09.015

Received: January 19, 2016

Accepted: January 26, 2016

Published: March 9, 2016 